\title{
Inequality and Group Participation: Theory and Evidence from Rural Tanzania
}

\author{
Eliana La Ferrara* \\ Bocconi University and IGIER
}

Revised: December 2000

\begin{abstract}
This paper investigates the determinants of group membership, and in particular the effect of income inequality on individual incentives to join economic groups. Drawing on a simple model, we show that an increase in inequality has an ambiguous effect and that the type of access rule (open versus restricted access) is key in determining what income categories are represented in the group. Furthermore, the shape of the income distribution can be crucial to determine whether increased inequality leads to more or less group participation. Using survey data from rural Tanzania we find that inequality at the village level has a negative impact on the likelihood that the respondents are members of any group. This effect is particularly significant for relatively wealthier people, both when relative wealth is 'objectively' measured, and when it is 'subjectively' defined. However, when we disaggregate groups by type of access rule, we find that inequality decreases participation in open access groups when there are wide disparities at the bottom of the distribution, while it increases participation in restricted access groups when the disparities are around the middle and top part of the distribution. Finally, we assess the impact of inequality on various dimensions of group functioning.
\end{abstract}

Keywords: social capital, groups, clubs, participation, inequality

J.E.L. Classification: D71, D31, O12

\footnotetext{
${ }^{*}$ Correspondence: Istituto di Economia Politica, Università Bocconi, via Sarfatti 25, 20136 Milano, Italy. E-mail: eliana.laferrara@uni-bocconi.it
} 


\section{Introduction}

This paper investigates the determinants of participation in groups, and in particular the effect of heterogeneity on individual incentives to join groups that provide some shared economic benefits. The specific form of heterogeneity considered is wealth inequality. We address such questions as: Is group participation higher or lower in more unequal communities? When inequality increases, is it the 'poor' or the 'rich' who drop out of the groups? Does this depend on the type of access rule to the group? How are individual incentives affected by the shape of the distribution of wealth (i.e. by the fact that heterogeneity may be concentrated in the lower or in the upper quintiles of the distribution)?

These questions are relevant for a variety of reasons. First of all, they broaden our understanding of the consequences of inequality. Typically, the reasons why we care about income inequality have to do with poverty and with its material consequences. However, inequality also leads to social tensions and in general places stress on social structures. This paper can shed some light on the social consequences of inequality. Secondly, but not less importantly, by asking how inequality affects participation in groups this paper explores the determinants of 'social capital', namely of the stock of social norms, trust, and civic networks that characterize a society. Since the work of Putnam (1993), social capital has been shown to have important economic effects both at the micro and at the macro level. ${ }^{1}$ If social capital has indeed such positive economic effects, it becomes important to understand its determinants: why is it that different communities have different levels of social capital, and what can economic policy do to affect this stock? Given the difficulty of measuring such an intangible' asset as social capital, our analysis concentrates on one of its most important components, which is particularly straightforward to measure: membership in groups.

\footnotetext{
${ }^{1}$ At the micro level, the role of networks in shaping individual outcomes such as labor supply, welfare participation, criminal activities, and fertility has been studied, among others, by Case and Katz (1991) and by Bertrand, Luttmer and Mullainathan (2000). At the macro level, Knack and Keefer (1997) have found a positive association between social capital and output growth in a cross section of countries. In the context of developing economies, numerous studies have documented the key role played by community links in solving coordination problems and facilitating economic transactions when markets are missing or incomplete (see, among others, Wade (1988), Ostrom (1990), Isham, Narayan and Pritchett (1995), Narayan and Pritchett (1999)).
} 
The main contributions of this paper can be summarized as follows. In the theoretical section we present a simple model in which heterogeneous individuals can choose to join a group which provides an excludable good to its members, and we derive predictions on the equilibrium composition of the group and on its size under two alternative access rules. The first is one of 'open access', by which anyone can join provided he or she pays the cost. The second rule instead allows the members of the group to exclude someone by majority vote. We show that an increase in income inequality has an ambiguous effect both on group composition and on aggregate levels of participation, and that the type of access rule is key in determining what income categories are represented in the group. In particular, open access groups will be formed by relatively poor individuals, while the composition of restricted access groups will be unbalanced in favor of the relatively rich. We then analyze the impact of increased inequality on participation and show that it depends both on the access rule and on the shape of the income distribution. In particular, aggregate membership decreases under open access when heterogeneity increases in the lower part of the distribution, while participation can actually increase under restricted access if the upper part of the distribution is sufficiently skewed.

We test the predictions of the theory using survey data on rural households from Tanzania. Our main empirical results are the following.

( $i)$ Higher inequality in assets at the village level has a negative impact on the likelihood that the respondents are members of a group. This result holds when controlling for other kinds of heterogeneity and for the possible endogeneity of inequality.

(ii) Inequality acts differentially on rich and poor people: when inequality increases, it is the relatively richer who drop out of groups, possibly because they have less to gain. The motives behind the decision of the rich to withdraw from groups are explored using both objective and subjective measures of relative wealth. We find that, for given 'objective' wealth, those individuals who overestimate their relative rank in the village participate less when inequality increases.

(iii) The impact of inequality on participation depends on the shape of the distribution of wealth and on the access rule to the group. In particular, it is negative for open access groups when there are wide disparities at the bottom of the distribution, while it is positive for restricted access groups when the disparities are around the 
middle and top part of the distribution.

(iv) Finally, group functioning in more unequal communities displays the following features: decisions are less likely to be taken by vote; members tend to sort into homogeneous income and ethnic groups; they more often report poor group performance and misuse of funds; they interact less frequently, and in general they feel less encouraged to participate. These effects are estimated separately for different categories of groups.

Relatively little work has been done on this topic. On the empirical side, the determinants of participation in socio-political groups in US cities have been investigated by Di Pasquale and Glaeser (1999) and by Alesina and La Ferrara (2000). Di Pasquale and Glaeser find that social capital is positively associated with home ownership, while Alesina and La Ferrara find that individuals are less likely to join groups in unequal and racially fragmented communities. This paper differs from the above studies in two respects. First, it includes economic groups such as production cooperatives and credit associations, and not only socio-political groups. ${ }^{2}$ Secondly, the empirical evidence provided in this paper regards a developing country. Understanding group participation in developing countries is crucial because in those countries groups and networks serve many of the functions that elsewhere are served by formal institutions and market mechanisms (e.g. they provide access to informal insurance, credit, and even jobs).

This paper is also related to the literature on inequality and collective action. Starting with the seminal contributions by Olson (1965) and Bergstrom, Blume and Varian (1986), who predicted, respectively, a positive and a neutral effect of income inequality on public good provision, recent studies have emphasized the possibility that the impact of increased inequality on collective action may indeed be negative. ${ }^{3}$

\footnotetext{
${ }^{2}$ This implies that the theoretical framework underlying the impact of heterogeneity on participation will hinge on the asymmetry in benefits and contributions among different members, rather than on 'preferences' for homogeneity as in Alesina and La Ferrara (2000).

${ }^{3}$ Baland and Platteau (1997) have shown that increased inequality may lead to less collective action when the free rider problem gets worse for the poor and the set of contributors shrinks substantially. Baland and Ray (1997) study the problem under different specifications for the production function of the public good and find that if there is high complementarity among the inputs of rich and poor members, higher disparities in income may lead to less efficiency. Bardhan, Ghatak and Karaivanov (2000) show that when there are market imperfections in inputs that are complementary
} 
Our paper does not study public goods, but something that is closer to the notion of 'club goods'. ${ }^{4}$ However, it shares with the above literature the interest in the effects and the workings of inequality.

The remainder of the paper is organized as follows. Section 2 presents the model. Section 3 briefly describes the data set and comments on the trends in participation and group composition. Section 4 illustrates our empirical strategy. Section 5 contains the main results on the effect of inequality - and of heterogeneity in generalon individuals' decisions to join groups. In section 6 , an attempt is made to estimate the impact of inequality on aggregate outcomes at the group level, e.g. on group composition and functioning. The results are presented separately for different categories of groups, such as economic, religious, and political. Section 7 concludes.

\section{The model}

In this section we present a simple model of participation in groups in which the net benefits from participation vary with individual wealth. ${ }^{5}$ The model studies the impact of increased inequality on individual and aggregate levels of participation, comparing two possible mechanisms of group functioning. First, the 'open access' case, in which whoever wants to join a group is free to do it, provided he or she pays the dues. Second, the 'restricted access' case, in which the admission of a new

to the collective goods, the relationship between inequality and efficiency will typically be inverse U-shaped.

${ }^{4}$ In contrast with club models, where an exclusion mechanism is usually assumed, we will study group composition both when there is excludability and when there is unrestricted access to the group. For a model of jurisdiction formation in which the choice of the admission rule is endogenous, see Jehiel and Scotchmer (1997).

${ }^{5}$ The aim of the model is to highlight one of the possible channels through which income distribution and participation can be related. We study the case in which only one group can form. This assumption is made because we are interested in understanding the impact of inequality in settings in which individuals with different wealth cannot perfectly 'segregate' into homogeneous groups. On the other hand, it is not too irrealistic to think that this assumption may apply to some communities (e.g. villages) whose small scale does not allow for the coexistence of many groups of the same type. The extension of our results to the case of multiple groups is discussed in section 2.3 . 
individual into a group must be agreed upon by a majority of the members. The key results delivered by the model can be summarized in four points:

i) Overall, inequality has an ambiguous impact on participation. Whether membership decreases or increases when there is more dispersion in wealth levels among the population depends in fact on the access rule and on whether the initial group members have become more or less heterogeneous.

ii) Given that the net benefits from participation are assumed to be decreasing in individual wealth, in those cases where membership decreases with inequality we can expect the relatively richer individuals to stay out of the groups when inequality increases.

iii) Under open access, the equilibrium composition of the group contains all the poorest individuals up to a threshold level of wealth. In this case, the effect of inequality depends on the shape of the income distribution at the bottom: if the increased dispersion in wealth makes the individuals below the wealth threshold more heterogeneous, participation will go down.

$i v$ ) Under restricted access, group composition is unbalanced in favor of the rich, and the impact of inequality depends on the shape of the income distribution around the mean and the top. In particular, participation can increase with inequality if the 'median voter' in the group becomes richer and wishes to extend membership to decrease his or her share of the costs.

\subsection{Setup}

Consider a continuum of individuals uniformly distributed on the interval $[0,1]$ and ranked according to their wealth $y_{i}$ so that the poorest individual has index 0 and the richest 1 . We denote the initial distribution of wealth by $\left\{y_{i}\right\}$. Each individual can choose whether or not to participate in a group that provides an excludable good to its members. This good is consumed in the same (fixed) quantity by all and only the members of the group. Let $H$ be the set of individuals who join the group. The total cost of providing the good is assumed to be fixed and equal to $C$. This cost is covered through a proportional tax on members' wealth: ${ }^{6}$

\footnotetext{
${ }^{6}$ All our qualitative results hold under a more general tax schedule $t(i)$, as long as $t(\cdot)$ is strictly increasing in $i$. While particularly convenient from an analytical point of view, the assumption of a
} 


$$
C=\int_{i \in H} t y_{i} d i
$$

The tax rate is assumed to be exogenous and, from the above expression, is decreasing in the size of the group and in the wealth of the participants: ${ }^{7}$

$$
t=\frac{C}{\int_{i \in H} y_{i} d i} .
$$

In order to abstract from the free-rider problem, we assume that individual wealth is observable and that whoever does not pay the fee $t y_{i}$ cannot have access to the good provided by the group. Also, in what follows we exclude the possibility of side payments among individuals.

Everyone has the same preferences over the good provided by the group, represented by the continuous utility function $u(\cdot)$. We assume that the quality of the good is the same for every member and is decreasing in the size of the group, say because of congestion. Let $H$ indicate the size of the group, with a slight abuse of notation. We assume that the 'reduced form' utility function over group size, $u(H)$, is continuously differentiable and that

$$
u^{\prime}(H)<0 ; u^{\prime \prime}(H) \leq 0 .
$$

Assumption (A1) says that the utility derived from joining the group decreases at an increasing rate with group size. ${ }^{8}$ Any individual who does not join the group gets a reservation utility $u(0) \equiv \bar{u} \geq 0$.

Total utility depends on group size and on income net of payments to the group, so that for an individual $j$ who does (or does not) join the group, total utility is, respectively: ${ }^{9}$

proportional tax can be motivated, for example, by the existence of informational contraints which prevent the use of more complex tax schemes. In section 2.3 we will discuss the consequences of the adoption of a lump-sum tax instead of a proportional tax.

${ }^{7}$ For a model in which the tax rate is endogenously determined by voting, see Roberts (1977).

${ }^{8}$ In general, we can think that initially there may be utility gains, rather than losses, from having more people in the group, and that congestion would take place only beyond a certain group size. We choose to ignore this possibility and to incorporate all positive effects if increased group size through the cost reduction channel.

${ }^{9}$ Both the assumption that $u(H)$ is independent of $i$ and the assumption that the reservation 


$$
U(j) \equiv u(H)+\left(1-\frac{C}{\int_{i \in H} y_{i} d i}\right) y_{j} \quad \text { for } j \in H
$$

We can now consider the equilibrium group size and composition under two alternative regimes.

\subsubsection{Open access group}

The first regime is one in which anyone is allowed to join the group, with or without the consent of the other members. We will call this the 'open access' group. In this case, the equilibrium size of the group must be self-enforcing, in the sense that all and only the individuals who obtain a positive net benefit from participating are in the group. This is captured in our definition of an open access (OA) equilibrium:

Definition 1 A group $H$ is an $\boldsymbol{O A}$ equilibrium if the following two conditions hold:

(i) no $j \in H$ wishes to leave $H$;

(ii) no $j \notin H$ wishes to join $H$.

The above definition amounts to saying that group $H$ will be formed by all and only the individuals $j$ for whom the following participation constraint is satisfied:

$$
u(H)-\frac{C}{\int_{i \in H} y_{i} d i} y_{j} \geq \bar{u}
$$

Proposition 2 In an OA equilibrium the group is formed by the poorest $\left[0, h^{*}\right]$ individuals, where $h^{*}$ is the largest root of the equation:

$$
u(h)-\frac{C}{\int_{0}^{h} y_{i} d i} y_{h}=\bar{u}
$$

utility $\bar{u}$ is the same for everyone may seem unrealistic. For the sake of parsimony, we choose to concentrate all wealth effects in the cost of participation, $t y_{i}$, but we could obtain analogous results by letting the gross benefits from participation and/or the outside option vary across individuals with different wealth. All we really need in the following analysis is some monotone relationship between the benefit from participation in excess of individual contribution and reservation utility on the one hand, and individual wealth on the other. 
Proof: Unless otherwise stated, all proofs are in appendix A.

In what follows we will often refer to $h^{*}$ as the 'marginal' member. Proposition 1 is a consequence of the fact that, when individual contributions increase with wealth, the net utility from participation is higher for the poorer members than for the richer ones. In fact the benefit from a given level of congestion is the same for everyone (first addendum on the left hand side of (3)), while the cost is higher for richer people (second addendum). There is a threshold level $h^{*}$ beyond which the burden of financing group activities would be too heavy for the richest individuals to bear, and they prefer to stay out of the group. All we need to know to predict group size is then the identity of the last richest member, which is the $h^{*}$ solution of (4).

\subsubsection{Restricted access group}

Consider now the case where the members can regulate access to the group, effectively preventing someone from joining or expelling a member they no longer want. We will maintain the assumption that the act of joining must be voluntary, i.e. the group can decrease its size without the consent of the involved party, but cannot increase it unless the new member agrees to join. Decisions within the group are taken by majority rule. Note that since for given group size individual preferences are strictly monotone in individual wealth, the member with median wealth is decisive. The extensive form of the game can be described as follows.

1. An initial group $H_{0}$ is given. ${ }^{10}$

2. The individual who has the median wealth among the members of the group proposes a new group $H_{1}$.

3. A majority vote is taken by the members of $H_{0}$ on the proposal $H_{1}$.

4a. If a majority votes against $H_{1}$, the original group $H_{0}$ remains in place.

4b. If a majority votes in favor of $H_{1}$, then:

4b_1. If all the new members of $H_{1}$ accept to stay in the group, $H_{1}$ replaces $H_{0}$.

4b_2. If any member of $H_{1}$ refuses to join, the original $H_{0}$ is reinstated.

5. Taxes are levied on the members of the final group (be it $H_{0}$ or $H_{1}$ ), the good is provided to them, and the game ends.

\footnotetext{
${ }^{10} \mathrm{We}$ are not interested in how the original group is formed. One can think for example of a random draw by nature, both in terms of size and of composition of the group.
} 
We next define our equilibrium concept under this restricted access (RA) regime.

Definition 3 A group $H_{0}$ is a $\boldsymbol{R A}$ equilibrium if the following two conditions hold:

(i) no $j \in H_{0}$ wishes to leave $H_{0}$;

(ii) $H_{1} \equiv H_{0}$, i.e. given the initial size and composition of the group, the median wealth member does not propose to alter it.

The following consideration can help understand our definition of a RA equilibrium. Note that any median member would always like to expel the bottom half wealth members of an initial group $H_{0}$ and include richer people in their place, i.e. shift the composition of the group to the right: this way congestion could be maintained the same and taxes decreased. In this effort, he would always be supported by the majority (the top half members). An equilibrium is reached when the size and composition of the group is such that: all the members get a higher utility from staying in the group than from leaving (condition $(i)$ in the definition); and no richer individual beyond the current top wealth member would agree to join the group, so it is not profitable for the median member to propose a change (condition (ii) in the definition). Alternatively, an RA equilibrium can be seen as the group chosen by a median member who maximizes his or her utility across the set of groups all of which will have him or her as a member.

Notice that in this framework the median member is given one chance to alter the composition of the group and then the game ends. In other words, the median member does not have to worry about the fact that, if group composition shifts right, in the following period he or she will no longer be 'median' and the new decisive individual may choose to move even more to the right, so that eventually the utility of the original median voter may be lower than under the initial configuration. While more satisfactory from a dynamic point of view, the latter approach would yield a larger set of equilibria. We choose therefore to adopt the seemingly more 'myopic' game structure described in the text in order to get sharper predictions on the equilibrium outcome. This way we obtain a 'fixed point' type of equilibrium, in which group size and composition are optimal for the median member even if he or she were free to alter it without risking 'unraveling' in the future. In the terminology of Roberts (1999), who develops a fully dynamic framework for voting equilibria in clubs, we are restricting our attention to an 'extrinsic' steady state. 
Lemma 4 Any group that is a RA equilibrium must be a single interval.

Given the above lemma, the equilibrium can be found by choosing the boundaries of a generic interval $\left[h_{1}, h_{2}\right]$ that maximize the net utility from joining the group for the median voter $\left(h_{1}+h_{2}\right) / 2$ within this group, provided that the participation constraint holds for all the individuals in $\left[h_{1}, h_{2}\right]:^{11}$

$$
\begin{gathered}
\max _{0 \leq h_{1}<h_{2} \leq 1} u\left(h_{2}-h_{1}\right)-\frac{C}{\int_{h_{1}}^{h_{2}} y_{i} d i} y_{\left(h_{1}+h_{2}\right) / 2} \\
\text { s.t. } u\left(h_{2}-h_{1}\right)-\frac{C}{\int_{h_{1}}^{h_{2}} y_{i} d i} y_{h_{2}} \geq \bar{u}
\end{gathered}
$$

The solution to the problem is described in the following proposition.

Proposition 5 Depending on the functional form of $u(\cdot)$ and on the wealth distribution $\left\{y_{i}\right\}$, in equilibrium the group can take one of two forms:

Case $A:\left[h_{1}^{*}, 1\right]$, where $h_{1}^{*}$ is the solution to

$$
-u^{\prime}\left(1-h_{1}\right)-\frac{C}{\int_{h_{1}}^{1} y_{i} d i}\left[\frac{\partial y_{\left(h_{1}+1\right) / 2}}{\partial h_{1}}+\frac{y_{h_{1}} y_{\left(h_{1}+1\right) / 2}}{\int_{h_{1}}^{1} y_{i} d i}\right]=0
$$

Case $B:\left[h_{1}^{* *}, h_{2}^{* *}\right]$, where $h_{1}^{* *}, h_{2}^{* *}$ and $\lambda$ solve

$$
\begin{gathered}
-u^{\prime}\left(h_{2}-h_{1}\right)(1+\lambda)-\frac{C}{\int_{h_{1}}^{h_{2}} y_{i} d i}\left[\frac{\partial y_{\left(h_{1}+h_{2}\right) / 2}}{\partial h_{1}}+\frac{y_{h_{2}}\left(y_{\left(h_{1}+h_{2}\right) / 2}+\lambda y_{h_{2}}\right)}{\int_{h_{1}}^{h_{2}} y_{i} d i}\right]=0 \\
-u^{\prime}\left(h_{2}-h_{1}\right)(1+\lambda)-\frac{C}{\int_{h_{1}}^{h_{2}} y_{i} d i} * \\
* \quad\left[\frac{\partial y_{\left(h_{1}+h_{2}\right) / 2}}{\partial h_{2}}-\frac{y_{h_{2}} y_{\left(h_{1}+h_{2}\right) / 2}}{\int_{h_{1}}^{h_{2}} y_{i} d i}+\lambda\left(\frac{\partial y_{h_{2}}}{\partial h_{2}}-\frac{y_{h_{2}}^{2}}{\int_{h_{1}}^{h_{2}} y_{i} d i}\right)\right]=0 \\
u\left(h_{2}-h_{1}\right)-\frac{C}{\int_{h_{1}}^{h_{2}} y_{i} d i} y_{h_{2}}=\bar{u}
\end{gathered}
$$

where $\lambda \geq 0$ is the multiplier on the participation constraint (6).

\footnotetext{
${ }^{11}$ Notice that in (6) we only write one constraint, namely that for the richest member $h_{2}$. In fact given that the net utility from joining the group is strictly decreasing in $y_{j}$ for given group size, if the participation constraint holds for $h_{2}$, it will necessarily hold for any $j \in\left[h_{1}, h_{2}\right]$.
} 
Case A describes an equilibrium in which the group is formed by the richest segment of the population. In case B, instead, both the low and the top end of the wealth scale are out of the group, the former because they are not allowed to join (though they would like to), and the latter because they choose not to (the tax burden is relatively too high for them). Compared to the OA equilibrium, the possibility to exclude people from the group generates a composition unbalanced in favor of the rich. A poor member is always less desirable than a rich one because it generates the same congestion and contributes less resources.

\subsection{Income distribution, group composition and size}

Starting from the initial wealth distribution $\left\{y_{i}\right\}$, we now consider the effects of an increase in inequality taking the form of a redistribution of wealth from the poor to the rich. In particular, we assume that the new wealth distribution $\left\{\widetilde{y}_{i}\right\}$ has the following characteristics:

$$
\begin{aligned}
& \int_{0}^{1} \widetilde{y}_{i} d i=\int_{0}^{1} y_{i} d i \\
& \forall i<i^{\prime}, y_{i}<y_{i^{\prime}} \Longrightarrow \widetilde{y}_{i}<\widetilde{y}_{i^{\prime}} \\
& \exists \widehat{i} \text { s.t. } \widetilde{y}_{\hat{i}}=y_{\hat{i}} \text {, and } \widetilde{y}_{i}<(>) y_{i} \text { for all } i<(>) \widehat{i}
\end{aligned}
$$

Assumption (A4) says that aggregate wealth is unchanged. Under (A5), each individual maintains the same wealth ranking. Finally, (A6) says that there is some individual $\widehat{i}$ whose wealth is the same as under the original distribution, all the people in $[0, \widehat{i})$ being poorer than before, and all those in $(\widehat{i}, 1]$ being richer. ${ }^{12}$

In the present context, in which only one group is formed, the aggregate level of participation coincides with group size. Will participation, as measured by group size, be higher or lower under the more unequal distribution of income?

\footnotetext{
${ }^{12}$ Of these assumptions, only (A4) is really needed, while (A5) and (A6) could be dispensed with. Suppose in fact that individual ranking under $\left\{\widetilde{y}_{i}\right\}$ changed compared to that under $\left\{y_{i}\right\}$. In this case, the arguments provided below could be applied in the same way by simply re-sorting individuals in ascending wealth order and studying whether the individual that under the new distribution occupies the 'marginal position' $h\left(\right.$ or $\left.h_{1}^{*}, h_{1}^{* *}, h_{2}^{* *}\right)$ is richer or poorer than before.
} 


\subsubsection{Inequality under open access}

When anyone is free to join the group, the impact of increased inequality is described by the following proposition.

Proposition 6 Let $h^{*}$ be the solution to (4). An increase in inequality taking the form described in (A4)-(A6) will decrease participation if and only if

$$
\frac{\widetilde{y}_{h^{*}}}{y_{h^{*}}}>\frac{\int_{0}^{h^{*}} \widetilde{y}_{i} d i}{\int_{0}^{h^{*}} y_{i} d i}
$$

Corollary 7 If (11) holds, the group that forms under $\left\{\widetilde{y}_{i}\right\}$ is constituted by the poorest $\left[0, h^{\prime}\right]$ individuals, where $h^{\prime}<h^{*}$.

Intuitively, the condition expressed in proposition 4 requires the relative increase (decrease) in the wealth of the marginal member $h^{*}$ to be larger (smaller) than the cumulative change in the wealth of the poorer members. We have seen, in fact, that each individual's incentive to join the group depends on his or her relative wealth vis-a-vis that of the other participants. Consider the case in which individual $h^{*}$ is richer under the new wealth distribution, i.e. $\widetilde{y}_{h^{*}}>y_{h^{*}}$. In this case, (11) holds unambiguously because the right-hand side is less than unity by construction. Individual $h^{*}$ is now 'too rich', and the other members 'too poor', for $h^{*}$ to benefit from participation.

If, on the other hand, $\widetilde{y}_{h^{*}}<y_{h^{*}}$, it can be profitable for $h^{*}$ to belong to the group as long as he or she has become sufficiently poor and $\widetilde{y}_{h^{*}}$ is close to that of the rest of the individuals in $\left[0, h^{*}\right)$, as depicted for example in figure 1a. In this case group size may actually increase with inequality, because the many people who have become poor get comparable benefits from participation and can gain by extending membership to decrease per-capita costs. Conversely, if $\widetilde{y}_{h^{*}}<y_{h^{*}}$ but (11) holds, as depicted for example in figure 1b, participation will be lower under the new distribution of wealth.

\section{[Insert figure 1]}

To sum up, under open access an increase in wealth inequality has an ambiguous effect on group size. Roughly speaking, the effect is negative if the redistribution leads to more inequality in the bottom part of the distribution; it can be positive 
if the redistribution benefits few rich people at the expense of a large mass of poor people so that there is relatively more equality at the bottom of the distribution. In all instances, if participation does decrease, it is the relatively richer members who choose to drop out. In the empirical section of this work, we will test all these implications.

\subsubsection{Inequality under restricted access}

When access to the group can be regulated by its members, the effect of inequality on participation is even more ambiguous. In what follows we discuss the results qualitatively. The formal analysis for case $\mathrm{A}$ is relegated to appendix $\mathrm{A} .{ }^{13}$

Let us start by recalling that, ceteris paribus, the 'ideal' group size is increasing in individual wealth. In fact any increase in size brings the same congestion to all the members, but generates greater savings for the richer ones through lower tax rates. The equilibrium size chosen by the median voter in a RA equilibrium is a compromise between the relatively large group sizes desired by the top half members and the relatively small ones preferred by the bottom half members. The key factor for assessing the impact of increased inequality on equilibrium group size will therefore be the new relative wealth of the median voter vis-a-vis the rest of the group.

Consider first case A, where the group under the initial distribution of wealth was constituted by $\left[h_{1}^{*}, 1\right]$. By assumption (A4), under $\left\{\widetilde{y}_{i}\right\}$ the aggregate wealth of the individuals in $\left[h_{1}^{*}, 1\right]$ is higher. This means that, if group size stayed the same, the tax rate required to cover the cost $C$ would now be lower. Loosely speaking ${ }^{14}$, if the

\footnotetext{
${ }^{13}$ If there are multiple equilibria, the conditions we derive on the impact of inequality on participation must be intended to hold locally around each of the equilibria. In appendix A, however, we show that, under mild sufficient conditions on the shape of the wealth distribution, the RA equilibrium type $\mathrm{A}$ is unique, hence for that case our conclusions hold globally.

A formal treatment of case B is not reported due to the large number of possibilities arising from the fact that in case B nothing can be said a priori on the aggregate wealth of group members under the new versus the old distribution of income. For this case, we therefore choose to give a qualitative account of the possible ambiguities.

${ }^{14}$ Notice that in general the individual who was the median member under the initial wealth distribution will no longer be the median member under $\left\{\widetilde{y}_{i}\right\}$. All we say in what follows should be read as saying that if the same individual were still median, he or she would no longer be optimizing by choosing the same group size, hence group size must change, in one direction or the other.
} 
median member $\left(h_{1}^{*}+1\right) / 2$ had the same (or lower) wealth than before, as in figure $2 \mathrm{~b}$, he would certainly be better off by reducing the level of congestion and choosing a smaller group size, say $\left[h_{1}^{\prime}, 1\right]$, with $h_{1}^{\prime}>h_{1}^{*}$. If, on the other hand, the median voter had become so rich to actually benefit from further decreases in tax rates (see figure 2a), participation may actually increase and the new lower bound $h_{1}^{\prime}$ may be smaller than $h_{1}^{*}$.

\section{[Insert figure 2]}

Consider now case B. Under the original distribution of wealth, the group was joined by the individuals in $\left[h_{1}^{* *}, h_{2}^{* *}\right]$ defined in proposition 3 , where the richest member $h_{2}^{* *}$ was held at the reservation utility $\bar{u}$. Take the case where the original 'median member' $\left(h_{1}^{* *}+h_{2}^{* *}\right) / 2$ is richer under $\left\{\widetilde{y}_{i}\right\}$, and thus wants to extend membership. If the increase in $h_{2}^{* *}$ 's individual wealth is particularly high and the decrease in the tax rate is not large enough, $h_{2}^{* *}$ may actually drop out of the group. More interestingly, contrary to case A where the total wealth of the participants is necessarily higher

under the new income distribution, in case B it is possible that $\int_{h_{1}^{* *}}^{h_{2}^{* *}} \widetilde{y}_{i} d i<\int_{h_{1}^{* *}}^{h^{* *}} y_{i} d i$. This implies that if the group remained as before, the tax rate should be higher and, unless $h_{2}^{* *}$ had become substantially poor and 'close' to the other members in wealth, his or her net utility would fall below $\bar{u}$. Under such circumstances, we would expect the relatively richer members to drop out and group composition to shift left.

To sum up, in the RA equilibrium an increase in inequality may either increase or decrease participation. Furthermore, in contrast with the OA case in which any decrease in group size happens with the richer members dropping out, in the RA case it can be the rich or the poor who leave the group, depending on the shape of the distribution of wealth.

\subsection{Discussion and extensions}

The analysis so far has assumed that only one group can form. A first question is whether our results generalize to the case where multiple groups can coexist. In this section we briefly address this question at the qualitative level. What makes the multiple groups setting interesting is the possibility that more inequality actually leads to an increase in participation by increasing the equilibrium number of groups. 
In fact from the local public finance - multicommunity literature we know that when heterogeneous agents can choose among multiple 'jurisdictions' they will stratify into homogeneous income groups (e.g. Epple and Romer (1991), Fernandez and Rogerson (1996)). While we can expect the results here obtained for a single group to hold within each of the multiple groups, it is possible to get contradicting results in the aggregate. Take for example the open access case, in which $N$ groups will form starting at 0 until some wealth level $\bar{h}$ beyond which no individual is part of any group. ${ }^{15}$ In this case an increase in inequality will shift the composition of each group to the left, and this may 'free up' some of the richer members so they can form an $N+1$ th group including some $j>\bar{h}$. Aggregate participation may in this case be higher, rather than lower, even in the open access case.

Another assumption in the above analysis was that members paid a proportional tax on income. This had two implications. The first was that anyone could sustain the costs of joining a group, because by definition only a fraction of their income was taken. The second was that for the whole group a richer individual was preferable to a poor one, because he or she contributed more. This generated our 'sorting' result. Suppose instead that group activities were financed through an exogenous lump-sum tax, $T$. In this case a new constraint should be added to the problem, namely that every member $i$ of a group of size $H$ can afford paying the dues: $y_{i} \geq T=C / H$. In the open access - single group case our result that the group is formed by the poorest $\left[0, h^{*}\right]$ individuals would no longer hold. First of all, the very poorest individuals may not be able to afford the costs of participation. Second, within the set of individuals whose income exceeds $T$ no prediction could be made on who exactly would join the group. All the model could determine is an equilibrium group size at which the net utility for any member exactly equals the reservation level $\bar{u}$. In this case the presence of heterogeneity in preferences and/or in individual outside options would deliver predictions on who should have an incentive to join. ${ }^{16}$

\footnotetext{
${ }^{15}$ The reason we can get multiple groups under open access, without all poor individuals flocking to the richest group, is that there is a trade off between size and tax rates. In other words, if the equilibrium size of the groups increases as we move from 0 to $\bar{h}$, the marginal member of the poorest group, say $h_{1}$, may be indifferent between staying in group 1 with high taxes and low congestion, and joining the immediately richer group 2 which has a lower tax rate and more congestion.

${ }^{16}$ For example, if individual outside options $\bar{u}_{i}$ were increasing in $i$, we could still predict that
} 
Regarding the decision process in the restricted access model, we have made the assumption 'one head one vote'. Realistically, in many groups the relatively richer individuals may have greater influence (direct or indirect) on the decisions. If this feature were incorporated in our analysis, it would reinforce the possibility that an increase in inequality leads to an increase of participation, thus accentuating the difference between the OA and the RA equilibria.

Finally, we choose to disregard the possibility that altruism may affect individual decisions to join groups (or to admit people into a group). Any assumption in this direction would of course affect our results.

\section{The data}

In what follows we turn to the empirical analysis to try and shed light on some of the ambiguities present in the theory and to test the predictions of the model. The data we use come from two surveys conducted by the World Bank: the Tanzania Social Capital and Poverty Survey (SCPS) of 1995 and the Tanzania Human Resource Development Survey (HRDS) of 1993. The SCPS sampled 1376 rural households, asking a broad set of questions on group membership, group composition and performance, and also on the values and degree of social ties in the community. For approximately half of the households in the sample, data on demographic characteristics and expenditure was also collected. An alternative source of information on village-level aggregates is the HRDS: although the surveyed households may be different, the clusters of the social capital survey are all comprised in this latter, broader survey. Where useful to remedy the incomplete coverage of the SCPS, this coincidence will be

the group will be formed by an interval $\left[h_{0}, h^{*}\right]$, where the lower bound $h_{0}$ is defined by the budget constraint $y_{h_{0}}=C /\left(h^{*}-h_{0}\right)$ and the upper bound $h^{*}$ is defined by the indifference condition $u\left(h^{*}-h_{0}\right)-C /\left(h^{*}-h_{0}\right)=\bar{u}_{h^{*}}$. In this case, it is still true that if participation decreases when inequality increases, it is the relatively richer people who stay out of the group. The introduction of a lump-sum tax modifies the analysis of the RA group in a more substantial way, because it is no longer true that the median voter would be made better off by a one time shift in the composition of the group to the right. Enriching the model with the possibility of idiosyncratic income shocks, a limited liability argument may push in the direction that a rich individual is relatively more 'desirable' than a poor one because he or she has a higher probability of being able to pay the fee in the event of an adverse shock. 
exploited. In this section, some descriptive statistics from the SCPS will be presented to gain some insight into the diffusion and characteristics of associational activity in our sample. ${ }^{17}$

[Insert table 1]

According to the SCPS, 72 percent of the individuals in the sample were members of some group, the average number of groups per participant being 1.6. Table 1 lists the main types of groups, reporting the percentage of the total sample who belong to the given group(s). We will classify the various groups under three broad categories: (i) religious, such as churches (joined by $15 \%$ of the respondents), Muslim groups and mosques (6\%); (ii) political (12\%); and (iii) economic, including burial societies $(12 \%)$, women's groups (5\%), farmers' groups (5\%), cooperatives $(2 \%)$, rotating credit associations (1\%), and dairy/cattle rearing groups (1\%). The characteristics of the different groups can be described with the help of table 2 .

[Insert table 2]

Panel A of the table contains information on the organizational rules of the groups, while panel B summarizes the degree of heterogeneity of the members. Starting from the top panel, for all categories of groups more than half of the respondents report that they joined voluntarily. A significant proportion of memberships for religious groups occur by birth (36\%); in the rest of the cases members of political and economic groups are either required to join (13\% and $16 \%$, respectively) or pay a fee $(35 \%$ and $19 \%$, respectively). Approximately 39\% of the respondents report that their groups are supported by an external agency: in most cases, the agency is an NGO $(39 \%$ for religious, $40 \%$ for political, and $54 \%$ for economic groups), other relevant funding sources being the government for political associations (53\%) and the church for religious ones (41\%). Enforcement mechanisms vary among the different categories: when there is a fee and members do not pay it, chances of being expelled are high for political and economic groups (about 40\%), while almost $80 \%$ of the members of religious associations report that nothing happens.

\footnotetext{
${ }^{17}$ For a detailed description of the Tanzania Social Capital and Poverty Survey, the reader is referred to Narayan (1997).
} 
In panel $\mathrm{B}$ we turn to the degree of heterogeneity of the members in terms of ethnic identity, type of economic activity, and income level. ${ }^{18}$ Regarding the ethnic composition of the groups, in the vast majority of the cases group membership is open to anyone: only for economic groups, $7 \%$ of the respondents say that the members all belong to the same clan or tribe. ${ }^{19}$ Group members are also diverse in the type of activity from which they earn their living. Approximately 78 to 87 percent of the respondents consider the groups 'mixed' under this respect. Again, only for economic groups the fraction reporting that 'all' ('most') members make a living in the same way is significant, namely $7 \%(14 \%)$. In a separate question, the same individuals were asked whether the leaders of the groups made a living in a different way from the rest of the members: in this case, 32 to 34 percent of the people answered 'yes'. Finally, all groups seem to aggregate people with different income levels: only $1 \%$ of the respondents reported that the members were all rich or all poor, and 15 to 29 percent - depending on the type of group - said that there was little income diversity among the participants.

Overall, the evidence reported in panel B seems to suggest that the individuals in our sample do not sort into highly homogeneous groups. At least in principle, therefore, there is scope for differential incentive mechanisms among relatively rich and relatively poor people, as stressed by the theory.

\section{Empirical strategy}

The structural equations underlying our estimates can be presented as follows. The expected net benefit from participation for individual $i$ in village $v$ is:

\footnotetext{
${ }^{18}$ This data differs from the measures of heterogeneity we will use in the multivariate analysis under two respects: $(i)$ the figures in table 2 refer to heterogeneity within the group, while in our regressions we will link participation to heterogeneity in the whole village (as requested by the theory); ( $i i)$ the data in table 2 comes from individual responses to questions directly aimed at assessing homogeneity among group members. In the multivariate analysis, on the contrary, we will construct measures of heterogeneity starting from the primitives, i.e. from raw data on individual ethnicity, education, economic activity, income and assets.

${ }^{19}$ The relative importance of ethnic affiliation for this category of groups compared to the others is not surprising, given that tribal links can enlarge the scope for reciprocity and enforcement mechanisms in economic transactions (see e.g. La Ferrara (1997)).
} 


$$
B_{i v}^{*}=\beta^{\prime} X_{i v}+\gamma^{\prime} H_{v}+\delta G_{v}+\varepsilon_{i v}
$$

where $X_{i v}$ is a vector of individual characteristics, such as age, sex, education, and wealth; $H_{v}$ is a vector of village characteristics, such as average wealth, heterogeneity in education, in economic activity, and in tribe; $G_{v}$ measures assets inequality in village $v$, and $\varepsilon_{i v}$ is an error term normally distributed with mean 0 and variance $\sigma_{v}$. The vectors $\beta, \gamma$ and $\delta$ are parameters. We do not observe the 'latent' variable $B_{i v}^{*}$, but only the choice made by the individual, which takes value 1 (participate) if the expected net benefit is positive, and 0 (not participate) otherwise:

$$
\begin{aligned}
& P_{i v}=1 \text { if } B_{i v}^{*}>0 \\
& P_{i v}=0 \text { if } B_{i v}^{*} \leq 0
\end{aligned}
$$

The probit model (12)-(13) will be estimated, correcting for heteroskedasticity and clustering of the residuals at the village level. ${ }^{20}$

To account for the possibility of endogeneity or measurement error in our inequality variable, we will then estimate a linear probability model and instrument inequality using geographical variables. The two-stage-least-squares model estimated is in this case:

$$
\begin{aligned}
& P_{i v}=\beta^{\prime} X_{i v}+\gamma^{\prime} H_{v}+\delta G_{v}+\varepsilon_{i v} \\
& G_{v}=\mu^{\prime} \bar{X}_{v}+\psi^{\prime} H_{v}+\lambda Z_{v}+\eta_{v}
\end{aligned}
$$

where $P_{i v}$ is equal to 1 if individual $i$ in village $v$ is member of some group and 0 otherwise; $X_{i v}, H_{v}$ and $G_{v}$ are as above; $\bar{X}_{v}$ contains village level averages for the variables $X_{i v} ; Z_{v}$ is a vector of instruments; finally, $\beta, \gamma, \delta, \mu, \psi, \lambda$ are vectors of parameters. The variable $G_{v}$ is thus estimated as in (15) and its predicted value

\footnotetext{
${ }^{20}$ Strictly speaking, the equations in (13) refer to open access groups, because it is in those groups that the individual choice to participate is purely 'demand driven', i.e. only depends on perceived net benefits $B_{i v}^{*}$. For restricted access groups, membership depends both on individual willingness to join and on acceptance on behalf of the group. However, given that under the assumptions of our theory acceptance by the group should depend on the applicant's characteristics and on community characteristics, the reduced form for RA groups can also be reconducted to model (12)-(13).
} 
substituted into (14), correcting the standard errors. The key assumption for the two stage estimation of this linear probability model is that $Z_{v}$ is correlated with $G_{v}$ but uncorrelated with $\varepsilon_{i v}$.

We will also estimate model (12)-(13) separately for 'relatively rich' and 'relatively poor' individuals, to see if the coefficient on inequality, $\delta$, differs among the two subsamples. Regarding the role of the shape of the income distribution under different access rules, we will test the predictions of our model by estimating model (12)-(13) separately for OA and RA groups, and using inequality measures with varying degrees of sensitivity to the lower vs. upper part of the income distribution.

Finally, the last part of our empirical analysis will explore some issues not directly linked to the model presented in this paper, but which we find worth investigating given the richness of the data set. In particular, we will examine how inequality relates to relevant group characteristics, namely group composition and functioning. Summary statistics for all variables are reported in appendix B.

\section{$5 \quad$ Inequality and group membership}

\subsection{Basic regressions}

Table 3 presents our estimates of the basic model. The dependent variable is a dummy taking value 1 if the respondent -generally the head of the household- is member of at least one group. The individual controls include: age, sex, and education of the respondent; household size, and a dummy equal to one if the respondent has been living in the same village at least for the past ten years. Individual wealth is measured through an 'asset index' constructed in the survey by assigning predetermined weights to the ownership of various durable consumption goods. ${ }^{21}$ The average of this index at the village level, as well as the 'size' of the village in terms of population, are included among the regressors to control for potential differences in the 'demand' for participation across communities. Regional dummies are also included.

\footnotetext{
${ }^{21}$ The durable consumption goods and weights used were the following: van or truck, car, motorcycle, bicycle, sewing machine $=16$, radio $=8$, table $=6$, bed, clock or watch $=4$, chair $=3$, lamp $=2$. If the asset was not working, these weights were approximately halved.
} 
The explanatory variables in which we are most interested are measures of heterogeneity among residents in the village, and in particular:

i) inequality, measured with the Gini coefficient built from the assets index of all respondents from the village ${ }^{22}$

ii) tribal fragmentation, measured through the following 'fractionalization' index:

$$
F_{v}=1-\sum s_{k v}^{2} \quad k=1, \ldots, K_{v}
$$

where $s_{k v}$ is the share of respondents in village $v$ who belong to tribe $k$, and in each village there is a number $K_{v}$ of different tribes. This index represents the probability that two randomly drawn individuals from the same village belong to different tribes;

iii) heterogeneity in economic activity, measured with an index analogous to (16), where $k$ denotes an individual's economic activity rather than tribe; ${ }^{23}$

$i v$ ) heterogeneity in education, measured as the standard deviation of the highest grade in school obtained by household heads interviewed in the village.

\section{[Insert table 3]}

The first column of table 3 presents the baseline specification of our probit model, including individual and village controls but not heterogeneity measures. The age and sex of the respondent do not seem to matter very much, while education has a positive and significant impact on the probability of being member of a group. Household size and the length of residence in the village do not have a significant impact on participation. On the other hand, the size of the community in terms of population has a negative effect on participation rates, though not always statistically

\footnotetext{
${ }^{22}$ The choice of assets inequality as opposed to expenditure or land inequality is motivated by several considerations. First, compared to income inequality, inequality in assets is likely to be less endogenous, and a better measure of permanent inequality in the village. Second, the only land variable in the HRDS is the number and size of shambas (or gardens) owned by a household, which does not necessarily capture differences in wealth. For example, an individual who solely relies on farm labor and cultivates two shambas should not be considered richer than a government employee who may not own a shamba. Finally, the Gini coefficient built from assets displays much more variation than that built from expenditure or from land.

${ }^{23}$ The most common activities are: working on own farm, government employee, self-employed, and retired.
} 
significant at conventional levels. Average wealth in the village is positively associated with group membership, suggesting that participation may be a 'normal good'. ${ }^{24}$

In column 2 we introduce various measures of heterogeneity at the village level. Neither tribal fractionalization nor heterogeneity in education turn out to be significant in our regression. The diversity of economic activities is also not significant: one possible reason is that there is not much variation in this variable: almost 84 percent of the respondents belong to the same category, i.e. 'farmers'. On the contrary, the estimated coefficient on Gini is negative and significant at the 1 percent level: increased inequality in one's village has a negative effect on the likelihood that somebody will join a group. Based on the marginal coefficients of the probit model in table 3, an increase in Gini by one standard deviation decreases the probability of participating in a group by about 4 percentage points. This is quite a sizeable effect if compared to the other determinants of participation: for example, it is almost three times the effect of one more year of education.

In the last two columns we consider non linear effects of individual income on participation. This is partly to verify that our results on inequality are not a statistical artifact. ${ }^{25}$ We can see from column 3 that, when we introduce individual assets and its square, Gini retains a negative and significant coefficient. The coefficients on individual assets suggest that the relationship between individual wealth and participation is increasing and concave. Finally, in column 4 we further explore nonlinearities by introducing two dummies that indicate whether the respondent belongs to the first or the last wealth quartile. We find that they have, respectively, a negative and a positive coefficient, though not highly significant. On the other hand, the coefficient on inequality is quite robust and fairly stable in all these specifications.

\footnotetext{
${ }^{24}$ We must be careful in interpreting this link in a causal sense, given that higher wealth in the community might be a consequence (rather than a cause) of higher levels of social capital (see Narayan and Pritchett, 1999).

${ }^{25}$ In fact, if the relationship between individual income and group participation were concave and we omitted nonlinear income terms from the specification, we may find a negative and significant coefficient on Gini even if inequality per se were not a determinant of participation. In this case, adding nonlinear income terms to the regression should wipe out the effect of inequality. This point has been discussed in the health economics literature when assessing the impact of income inequality on health outcomes (see Gravelle (1998)).
} 


\subsection{Instrumenting Gini}

Before proceeding with more specific tests of our theory, we need to deal with the potential endogeneity of the variable Gini. One may conjecture that a high degree of participation may reduce inequality by generating opportunities of advancement for the poor in terms of education, diffusion of information, public good provision, etc. Also, villages prone to social activities may have higher levels of risk-sharing, which would attenuate the differences in expenditure among their members (though this would be less of a concern if we had a reliable measure of permanent wealth). Finally, we want to account for the possibility of measurement error in the variable Gini.

To address the above problems, we estimate a linear probability model using twostage-least-squares, and instrumenting Gini with the following geographic variables:

(i) the average precipitation in the 'critical month(s)', i.e. in those months of the growing season in which scarcity of rain can jeopardize the harvest the most. ${ }^{26}$ Given that agriculture is the main activity in rural Tanzania, we expect to find a negative relationship between this measure of rain and inequality in the village;

(ii) rainfall variability, i.e. the standard deviation of the monthly precipitation during the year. The higher this variability, the more vulnerable to shocks should be people who rely on farming to earn a living, hence the higher inequality;

(iii) average temperature during the year (in $\mathrm{C}$ degrees);

(iv) temperature variability, i.e. the standard deviation of monthly temperature;

(v) median distance of village households from the livestock market;

(vi) median distance of village households from the market for farm products;

(vii) a dummy for villages located in touristic areas, e.g. Kilimanjaro or other national parks, which plausibly have prospects for higher earnings by a few people.

The 2SLS estimated coefficient on Gini is -.43 (not too different from the one obtained without instrumentation), with a standard error of .26. The Hausman test

\footnotetext{
${ }^{26}$ The critical months were identified by looking at the patterns of rain in the different regions, e.g. unimodal versus bimodal (Gommes and Houssiau (1982)), and by checking the calendars for the relevant crops. The only year for which we could find monthly precipitation data minute by minute is 1987. Despite the lag between the year of the social capital survey and 1987, the latter is recognized as a 'typical' year in terms of precipitation (Gommes and Petrassi, 1994), and should therefore be adequate to relate to 'permanent' wealth as measured by asset ownership.
} 
fails to reject the joint null of weak exogeneity and no measurement error in Gini (p-value is .97), and according to the Sargan overidentification test our instruments are valid ( $\mathrm{p}$-value of .17). ${ }^{27}$ This seems to suggest that our concerns about reverse causation and measurement error are not warranted empirically.

\subsection{Differential impact of inequality for the rich and the poor}

An important question is whether the negative effect of inequality on participation holds across households with different wealth levels, or rather if there is a systematic tendency for richer (or poorer) individuals to drop out of groups when inequality increases. This question is addressed in table 4.

[Insert table 4]

In this table we estimate the impact of Gini on participation separately for 'relatively poor' individuals (column 1) and 'relatively rich' ones (column 2). 'Relative wealth' is defined under three different criteria (rows 1 to 3 ) to explore the mechanism underlying the effect of inequality on group membership. Each cell in table 4 thus reports the coefficient on Gini from a separate regression in which the sample is restricted to the category of individuals listed by column as identified by the criterium listed by row. As usual, in each regression the dependent variable is the participation dummy and the controls include all individual and community characteristics listed in column 3 of table 3 (in particular, they include individual assets).

In row 1 we start by considering individual rank in the wealth scale as 'objectively' defined by their asset ownership. For each village we compute wealth quintiles, and we split the sample between those individuals who belong to the bottom two quintiles (column 1), and those who belong to the top three ones (column 2). As we can see from the table, inequality has a negative and significant impact on participation for the latter category of individuals, but not for the former. Our interpretation of this result is that the economic gains from participation are asymmetric and that when inequality increases, so that low-income households become poorer and high-income ones become richer, the latter have less to gain from joining a group. This is quite

${ }^{27}$ The adjusted $\mathrm{R}$ square in the first stage regression is .61 , the first stage $\mathrm{F}$ statistic is $F(22,25)=$ 1.77 and its p-value is .08. 
plausible for groups such as, for example, burial societies or women groups, where the gains from participation are not proportional to individual wealth and where the rich have less to gain from participating relative to the poor. ${ }^{28}$

One may argue that relative wealth captures some unobservable individual characteristic that affects participation independently of the 'relative benefits' that can be obtained from the group. In rows 2 and 3 we address this concern by exploiting the nature of 'Participatory Poverty Assessment' of the SCPS. In addition to collecting information on asset ownership, this survey asked each respondent to rank his or her household on a scale from 1 to 5, 1 being 'very poor', 2 'poor', 3 'average', 4 'rich', and 5 'very rich'. Separately, a mixed group of people from the village was asked to agree on a definition for the five categories and then rank themselves and the households included in the survey sample according to those categories. ${ }^{29}$

In row 2 of the table the sample is split according to the respondents' own perception of their relative standing in the village. Column 1 reports the estimated coefficient on Gini for those individuals who define themselves 'very poor' or 'poor', column 2 for those who define themselves 'average', 'rich', or 'very rich'. Again, while the effect of inequality on participation is negative and significant for "relatively rich" individuals, it is not for "relatively poor" ones. Given that both regressions include individual 'objective' wealth among the controls, we can run the following thought experiment. Take two individuals with the same assets, and therefore with the same objective benefits and costs from participation, but with a different perception of their wealth: one who considers himself below average, and the other average or above. Now let those individuals face the same increase in inequality in their village. Our results suggest that the decision to participate in a group by the individual who considers himself below average will not be significantly affected, while that of the other will be negatively affected. Our interpretetion is that the divergence in their reaction to increased inequality may be due to the conviction that richer people have less to

\footnotetext{
${ }^{28}$ This evidence is consistent with other empirical studies of the determinants of collective action (e.g. Gaspart, Jabbar, Melard and Platteau (1998)), which show that participation -in the form of labor contribution to the provision of a public good - is higher for those individuals who can expect to benefit relatively more from the public good.

${ }^{29}$ The group evaluation process is described in Narayan (1997), ch.2. For an empirical analysis of the determinants of subjective welfare, see Ravallion and Lokshin (1999).
} 
gain from participating in groups with poorer people.

To investigate this hypothesis more in depth, we explore the subjective dimension of inequality by comparing an individual's own perception of his or her rank with the perception that the community has of that individual. In particular, we build a measure of 'subjective overestimation' subtracting the 1-5 score assigned to each respondent by the evaluation group from the score self-assigned by the respondent. A positive value of this variable indicates that the respondent perceives him or herself richer than the community does, and vice versa for a negative value. In row 3 we repeat our estimates splitting the sample between people who underestimate or correctly rank themselves (column 1), and people who overestimate themselves (column 2 ). We can see from the table that the negative effect of inequality on participation only holds for those people who overestimate their rank. Again, given that we are controlling for 'objective' asset ownership, this result may suggest that individuals who overestimate their rank believe that when inequality increases they will be relatively richer than the other potential members of the group and will have less to gain, hence they stay out of the group. ${ }^{30}$

Overall, the results in table 4 are consistent with the hypothesis that an individual's decision to join a group depends on the expected net benefits from participation, and that the way these benefits change with inequality depends on the individual's rank in the wealth scale, defined both 'objectively' and 'subjectively'. The plausibility of this interpretation will be reinforced in section 6 , where the analysis is conducted separately for different kinds of groups from which rich and poor people have different benefits.

\subsection{Skewedness of the income distribution and access rules}

We next investigate the relationship between the shape of the distribution of wealth and the impact of inequality under different access rules. In the top panel of table 5,

\footnotetext{
${ }^{30}$ Another possible interpretation is that the selection into either sub-sample is endogenous, e.g. it is because they are not part of any group that the wealth of individuals belonging to the second sub-sample is underestimated by the evaluation team. In order for this objection to be compelling, one should argue that the bias in the team's evaluation of those who are not members of any group is systematically in the direction of underestimating their wealth. However, it is very likely that such a bias, if it exists, would go in the opposite direction.
} 
our dependent variable is a dummy equal to 1 if the respondent belongs to and open access group (church, Muslim, and political groups) and 0 otherwise. In the bottom panel, the dependent variable takes the value 1 if the respondent is a member of a restricted access group (burial society, women group, farmers' association, dairy/cattle rearing group, coop, rosca) and 0 otherwise. Explanatory variables include individual and village controls, plus various measures of inequality. The idea is to exploit the fact that different measures are sensitive to different parts of the income distribution to link our results to the predictions of the theory.

[Insert table 5]

The first column of table 5 reports the marginal probit coefficient on asset inequality when the inequality index used is the Generalized Entropy with parameter equal to 2. This measure is very sensitive to wealth differences at the top of the distribution but not at the bottom. As we can see, in the bottom panel of the table it has a positive and significant coefficient, while in the top panel it is negative and not significant. A similar pattern obtains when the Gini coefficient is used (column two). Gini is in fact most sensitive to differences around the median. These findings are consistent with the analysis of section 2.2.2, where we showed that inequality can increase participation in restricted access groups if there are significant income disparities in the middle and top part of the distribution (see figure 2a).

In the third and fourth column of table 5 , instead, we use inequality measures very sensitive to the bottom part of the distribution, namely the Atkinson index (with parameter 2) and the standard deviation of the logarithm of assets. The results are now quite different: inequality is no longer significant in RA groups, while it has a negative and significant impact on participation in OA groups. This is consistent with the analysis in section 2.2.1, where we showed that increased inequality lowers participation if there are sufficient disparities in the lower part of the distribution (see figure 1b).

Another way to read these results is to look at table 5 by row. In open access groups (top panel) we fail to capture the negative impact of inequality if we use measures that do not discriminate sufficiently between situations where 'the poor are all poor' and situations where relevant differences exist within the bottom quintiles. We capture instead this impact when we use measures like Atkinson and the Standard 
Deviation of Logs. In restricted access groups (bottom panel), we capture the positive effect of inequality on participation when we use inequality measures which are sensitive to differences around the middle and top parts of the distribution, but we don't get significant results with the other measures. Having an accurate measure of the skewedness of the income distribution seems to matter to understand the differential impact of inequality on participation by the rich and the poor. ${ }^{31}$

\section{$6 \quad$ Inequality and group characteristics}

Finally, we address the question of whether inequality is systematically associated with certain characteristics of the groups, both in terms of composition and in terms of functioning. Table 6 presents the probit marginal coefficients from a set of regressions of various group characteristics on assets inequality, controlling for average assets in the village, heterogeneity in schooling and in economic activity, and tribal fractionalization. Leaving aside for the moment the last two columns, each row in the table refers to a different dependent variable (all dummies, listed on the left), and each column to a different type of group (listed on top). Each cell in columns 1 to 6 therefore reports the coefficient on Gini from a separate regression. ${ }^{32}$

The types of groups considered are: religious (church, mosque, or Muslim group), political, and five of the most widespread 'economic' groups: burial societies, women groups, farmers' associations, cooperatives and rotating saving and credit associations (ROSCAs). Burial societies are essentially a means of pooling resources to organize and pay for unexpected expenses such as funerals. There is in general only one burial society in a village, so that if rich and poor people want to participate, they will be members of the same society. While there are no fees, all members are supposed to pay and provide labor when someone dies. For this reason, we can think that poor people have relatively more to gain than rich people from being members in a burial society. Women groups can serve a variety of functions. Some of them are essentially political organizations, others serve religious or social purposes, others

\footnotetext{
${ }^{31} \mathrm{~A}$ similar pattern emerges when a single index is used (e.g. the Generalized Entropy or the Atkinson index) varying the values of the parameters.

${ }^{32}$ In general, the questions on group composition and functioning of the different groups were asked only to those individuals who reported that they were members of those particular groups.
} 
still serve economic functions. Among these are microenterprise activities such as tree planting, beer brewing, and credit provision. Again, the possibility to take part in this kind of activities is relatively less appealing for people at the top end of the income scale. Farmers' associations deal with agricultural production and fertilizers, and as such can comprise both rich and poor members. Finally, cooperatives and ROSCAs serve the usual functions described in the literature.

[Insert table 6]

The top half of table 6 shows the impact of inequality on group composition. In villages with higher inequality group members are generally more likely to belong to the same clan or tribe (row 1). They are also more likely to make a living in the same way (row 2) and less likely to be from a mixed income group (row 4), suggesting that when inequality increases people tend to sort into more homogeneous groups. It should be noted that these effects are significant in particular for burial societies, women groups, cooperatives and ROSCAs, i.e. those groups where the 'rich' have less to gain if the rest of the members become 'poorer'. For these groups the likelihood that the "members are all poor" is in fact higher the higher the inequality in the village (row 5). These findings are consistent with the interpretation on the differential impact of inequality for rich and poor people given above.

In the bottom half of table 6 group composition is taken as given and the question asked is: does higher inequality harm the functioning of a group in any way? Various aspects of group functioning are considered. First of all, in more unequal communities people are less likely to respond that decisions are taken by vote (row 6). There seems to be a tendency towards hierarchic decision-making, especially in those groups political and farmers' associations - where both rich and poor members coexist. This is of particular interest when evaluating the effect of inequality on 'participation' because, although this effect may not show up as a decrease in raw membership numbers, the nature of the groups may still be not very 'participatory'. Also, when inequality is higher members feel less "encouraged to participate" (row 7), again especially in religious and political groups, where members with different levels of wealth coexist.

When asked to evaluate the functioning of their groups, people living in villages with higher inequality are less likely to report that it is "good" or "excellent" (row 
8), although this relationship is statistically significant only for religious and political groups. Members of political groups tend to report that the disadvantage from participating in the group is that they are "misinformed" (row 9) when inequality is higher, consistently with the less democratic decision process noted above. On the other hand, for members of burial societies and women groups the main disadvantage seems to be bad economic management (row 10), e.g. misappropriation of funds by some member or unprofitable activities.

In villages with more income disparities, the likelihood that membership has increased in the past four years (row 11) is lower, which may be seen as an implicit assessment of bad performance. Finally, in more unequal areas groups themselves interact less frequently (row 12). The fact that the negative impact of inequality on many aspects of group functioning is especially significant for burial societies and women groups is of particular concern because it reveals a potentially perverse effect of inequality on groups that are already comprised of low-income individuals.

Columns 7 and 8 repeat the same exercise aggregating the single groups according to their access regime (open or restricted). For each regression, the coefficient on Gini is allowed to differ depending on whether the group is OA or RA. ${ }^{33}$ Interestingly, when the dependent variable regards group composition (rows 1 to 5 ), higher inequality leads to increased homogeneity in RA more than in OA groups, and the difference between the two coefficients is significant at less than 5 percent level in all but one case. This is consistent with the idea that exclusion rules allow members of RA groups to form a relatively homogeneous crowd, while OA groups do not manage to achieve much sorting. On the other hand, when the dependent variable refers to group functioning (rows 6 to 12) the negative impact of inequality is more pronounced for OA groups, and the difference is statistically significant in the case of decision making, participation, perceived good functioning, and sharing of information. In other words, when groups are not sorted by wealth, heterogeneity seems to harm group functioning

\footnotetext{
${ }^{33}$ More precisely, we estimate the following equation $Y_{i g v}^{*}=\gamma^{\prime} H_{v}+\delta_{O A} I_{g} G_{v}+\delta_{R A}\left(1-I_{g}\right) G_{v}+\varepsilon_{i g v}$ where $Y_{i g v}^{*}$ is the latent variable underlying the probit model for the characteristic of group $g$ reported by individual $i$ in village $v ; H_{v}$ and $G_{v}$ represent, respectively, village characteristics and the Gini coefficient computed from assets, as in equation (12). The novelty is the dummy $I_{g}$ which is equal to 1 if group $g$ is 'open access' and 0 otherwise. The coefficients $\delta_{O A}$ and $\delta_{R A}$ therefore capture the impact of inequality on the group characteristic listed by row separately for OA and RA groups.
} 
more than when exclusion rules are available.

\section{Conclusions}

This paper has attempted to understand the determinants of group membership and how groups function by looking at the role of heterogeneity, and in particular of wealth inequality. Using household level data from rural Tanzania, we have shown that people living in villages with higher inequality are less likely to be members of groups, and that this effect is more pronounced for relatively wealthier individuals. The shape of the distribution of wealth and the type of access rule to the group are also crucial factors affecting the relationship between inequality and participation. Finally, more dispersion in wealth levels seems to be associated with more homogeneity in group composition and with 'negative' outcomes in terms of group functioning. Though far from definitive, the evidence presented seems certainly suggestive and calls for a deeper investigation of the mechanisms through which heterogeneity and inequality affect individual incentives to participate in groups.

\section{Acknowledgments}

I am grateful to Abhijit Banerjee and Alberto Alesina for insightful discussions and suggestions. Useful comments were also provided by an anonymous referee, Philippe Aghion, Oriana Bandiera, Tim Besley, Francois Bourguignon, Micael Castanheira, Jean Drèze, Marcel Fafchamps, Emanuela Galasso, Roger Gordon, Caroline Minter Hoxby, Eric Maskin, Jonathan Morduch, Debraj Ray, Guido Tabellini, David Ulph and by seminar participants at Harvard University, 1998 NEUDC Conference at Yale, Bocconi University, University of Namur, LSE, The World Bank, Delta, Oxford University, University of Bologna and University of Ancona. I thank Deepa Narayan and Lant Pritchett for providing the Tanzania Social Capital and Poverty Survey data. The usual disclaimer applies. 


\section{References}

[1] Alesina, A., La Ferrara, E., 2000. Participation in heterogeneous communities. Quarterly Journal of Economics 115 (3), 847-904.

[2] Baland, J.-M., Platteau, J.-P., 1997. Wealth inequality and efficiency in the commons, Part I: The unregulated case. Oxford Economic Papers 49, 451-482.

[3] Baland, J.-M., Ray, D., 1997. Technical complementarities and the impact of inequality on collective action: An application to the commons. Mimeo.

[4] Bardhan, P., Ghatak, M., Karaivanov, A., 2000, Inequality and collective action problems. Mimeo.

[5] Bergstrom, T., Blume, L., Varian, H., 1986. On the private provision of public goods. Journal of Public Economics 29, 25-49.

[6] Bertrand, M., Luttmer, E., Mullainathan, S., 2000. Network effects and welfare cultures. Quarterly Journal of Economics 115 (3), 1019-1055.

[7] Case, A.C., Katz, L.F., 1991. The company you keep: The effects of family and neighborhood on disadvantaged youths. NBER Working Paper 3705.

[8] Di Pasquale, D., Glaeser, E., 1999. Incentives and social capital: Are homeowners better citizens?. Journal of Urban Economics 45 (2), 354-384.

[9] Epple, D., Romer, T., 1991. Mobility and redistribution. Journal of Political Economy 99, 828-858.

[10] Fernandez, R., Rogerson, R., 1996. Income distribution, communities, and the quality of public education. Quarterly Journal of Economics 111 (1), 135-164.

[11] Gaspart, F., Jabbar, M., Melard, C., Platteau, J.-P., 1998. Participation in the construction of a local public good: An application to watershed development in Ethiopia. Journal of African Economies 7 (2), 157-184.

[12] Gommes, R., Houssiau, 1984. Rainfall variability, types of growing seasons and cereal yields in Tanzania. Proceedings of the Technical Conference on Climate in Africa, No. 596, World Meteorological Organization. 
[13] Gommes, R., Petrassi, F., 1994. Rainfall variability and drought in Sub-Saharan Africa. Agrometeorology Series Working Paper No. 9, FAO.

[14] Gravelle, H., 1998. How much of the relation between population mortality and unequal distribution of income is a statistical artifact?. British Medical Journal $16,382-385$.

[15] Isham, J., Narayan, D., Pritchett, L., 1995. Does participation improve performance? Establishing causality with subjective data. World Bank Economic Review 9 (2), 175-200.

[16] Jehiel, P., Scotchmer, S., 1997. Constitutional rules of exclusion in jurisdiction formation. Working Paper No. 231, Graduate School of Public Policy, UC Berkeley.

[17] Knack S., Keefer, P., 1997. Does social capital have an economic payoff? A cross-country investigation. Quarterly Journal of Economics 112, 1251-1273.

[18] La Ferrara, E., 1997. Ethnicity and reciprocity: A model of credit transactions in Ghana. Mimeo.

[19] Narayan, D., 1997. Voices of the poor: Poverty and social capital in Tanzania. ESSD Studies and Monograph Series No. 20, The World Bank.

[20] Narayan, D., Pritchett, L., 1999. Cents and sociability: Household income and social capital in rural Tanzania. Economic Development and Cultural Change 47 (4), 871-897.

[21] Olson, M., 1965. The logic of collective action. Harvard University Press, Cambridge, MA.

[22] Ostrom, E., 1990. Governing the commons: The evolution of institutions for collective action. Cambridge University Press, Cambridge.

[23] Putnam, R., Leonardi, R., Nanetti, R., 1993. Making democracy work: Civic traditions in modern Italy. Princeton University Press, Princeton, NJ. 
[24] Ravallion, M., Lokshin, M., 1999. Subjective economic welfare. Policy Research Working Paper No. 2106, The World Bank.

[25] Roberts, K., 1977. Voting over income tax schedules. Journal of Public Economics 8, 329-340.

[26] Roberts, K., 1999. Dynamic voting in clubs. STICERD Discussion Paper No. TE/99/367, London.

[27] Wade, R., 1988. Village Republics. Cambridge University Press, Cambridge.

\section{Appendix A}

\section{Proof of proposition 1}

The first part of the proposition says that the group is formed by an interval of people, and in particular by the poorest $[0, h]$ individuals. This follows from the fact that, for given group size, the left-hand side of (3) is decreasing in $y_{j}$, hence in $j$. Therefore if $(3)$ is satisfied for some $j \in(0,1)$, then it must be satisfied for all $j^{\prime}<j$.

The second part of the proposition gives the 'identity' of the richest individual in the group, i.e. the value of $h$ for which the participation constraint is binding. Whether the solution to (4) is unique depends on the functional form of $u(\cdot)$, as well as on the distribution of $y_{i}$. We can gain some insights by looking at the derivative of the left hand side of (4) with respect to $h$ :

$$
u^{\prime}(h)-\frac{C}{\int_{0}^{h} y_{i} d i} \frac{\partial y_{h}}{\partial h}+y_{h}^{2} \frac{C}{\left(\int_{0}^{h} y_{i} d i\right)^{2}}
$$

An increase in $h$ has three effects. First of all, congestion increases, hence utility is lower (first addendum on the right-hand side of (A.1)). Second, for given tax rate, the cost paid by the $h$ th individual is higher because his or her wealth is higher (second term on the right-hand side). Finally, for given income level, the tax rate is lower because the fixed cost $C$ is divided among more members (third addendum in (A.1)). The sign of (A.1) will be positive if and only if this last 'tax rate effect' (positive) is stronger than the 'congestion' and 'taxable income' effects (negative). 
For $h \rightarrow 0$ the tax rate effect prevails, hence it is optimal to increase the size of the group beyond 0 . For $h \rightarrow 1$, on the other hand, two possibilities arise. The first, relatively uninteresting, is that the tax rate effect still prevails over the others so that the only stable group is the whole population. The second possibility is that (A.1) evaluated at 1 is negative. In this case there will be two solutions to (4), $h_{A}$ and $h_{B}$, where $h_{A}<h_{B}$. Of these, only $h_{B}$ is stable. In fact, if one increased infinitesimally the size of the group to $h_{A}+\varepsilon$ the participation constraint would still be met for the $\left(h_{A}+\varepsilon\right)$ th individual. The latter would be strictly better off by joining the group than by staying outside, hence group size would increase. This holds as long as $h$ 's net utility is above $\bar{u}$, i.e. until the richest member is the second root of (4), $h_{B}$. In the text we concentrate only on the stable equilibrium and refer to $h_{B}$ simply as $h^{*}$.

\section{Proof of Lemma 1}

Suppose not, e.g. $H$ is the union of two intervals $\left[h_{1}, h_{2}\right] \cup\left[h_{3}, h_{4}\right]$, where $0 \leq h_{1}<$ $h_{2}<h_{3}<h_{4} \leq 1$. Note that since (3) is satisfied for the individuals in $\left[h_{3}, h_{4}\right]$, then it must be satisfied for those in $\left(h_{2}, h_{3}\right)$. Let $\widehat{j}$ be the median income member of group $H$. If $\widehat{j} \in\left[h_{3}, h_{4}\right]$, then all individuals in $\left[\widehat{j}, h_{4}\right]$ - a majority - would be better off by keeping group size the same and exchanging some low income members $\left[h_{1}, \widehat{h}\right)$ for members in $\left[\widehat{h}, h_{3}\right)$, where $h_{1}<\widehat{h}<h_{3}$. In fact congestion would be the same but per capita taxes would be lower. If $\widehat{j} \in\left[h_{1}, h_{2}\right]$, then all individuals in $\left[\widehat{j}, h_{2}\right] \cup\left[h_{3}, h_{4}\right]$ - a majority — would be better off by keeping group size the same and exchanging some low income members $\left[h_{1}, \widehat{h}\right)$ for members in $\left[h_{2}, h_{3}\right)$, where $h_{1}<\widehat{h}<h_{2}$ and $\widehat{h}-h_{1}=h_{3}-h_{2}$. Therefore $H$ cannot be a RA equilibrium.

\section{Proof of proposition 2}

Let $\lambda \geq 0$ indicate the multiplier on the constraint (6), and $\mu \geq 0$ the multiplier on the constraint $h_{2} \leq 1$. The first order conditions to the problem are given by

$$
-u^{\prime}\left(h_{2}-h_{1}\right)(1+\lambda)-\frac{C}{\int_{h_{1}}^{h_{2}} y_{i} d i}\left[\frac{\partial y_{\left(h_{1}+h_{2}\right) / 2}}{\partial h_{1}}+\frac{y_{h_{1}}}{\int_{h_{1}}^{h_{2}} y_{i} d i}\left(y_{\left(h_{1}+h_{2}\right) / 2}+\lambda y_{h_{2}}\right)\right]=0
$$




$$
\begin{gathered}
u^{\prime}\left(h_{2}-h_{1}\right)(1+\lambda)-\mu-\frac{C}{\int_{h_{1}}^{h_{2}} y_{i} d i} * \\
*\left[\frac{\partial y_{\left(h_{1}+h_{2}\right) / 2}}{\partial h_{2}}-\frac{y_{h_{2}} y_{\left(h_{1}+h_{2}\right) / 2}}{\int_{h_{1}}^{h_{2}} y_{i} d i}+\lambda\left(\frac{\partial y_{h_{2}}}{\partial h_{2}}-\frac{y_{h_{2}}^{2}}{\int_{h_{1}}^{h_{2}} y_{i} d i}\right)\right]=0 \\
\lambda\left[u\left(h_{2}-h_{1}\right)-\frac{C}{\int_{h_{1}}^{h_{2}} y_{i} d i} y_{h_{2}}-\bar{u}\right]=0, \lambda \geq 0,[\cdot] \geq 0, \\
\quad \text { with complementary slackness. }
\end{gathered}
$$

$$
\begin{aligned}
\mu\left(1-h_{2}\right)= & 0, \mu \geq 0,\left(1-h_{2}\right) \geq 0, \\
& \text { with complementary slackness. }
\end{aligned}
$$

Claim 1: Either $h_{2}=1$, or $\lambda>0$, or both.

Proof of Claim 1. By contradiction. Suppose $h_{2}<1$ and $\lambda=0$, i.e. (3) is not binding for $h_{2}$. Then the median member would be strictly better off in the group $\left[h_{1}+\varepsilon, h_{2}+\varepsilon\right], \varepsilon \rightarrow 0^{+}$. By continuity of the left hand side of $(3), h_{2}+\varepsilon$ will have a net benefit no lower than $\bar{u}$ and will accept to join the group. Therefore the initial group was not an equilibrium.

Case $\mathrm{A}$ in the text is obtained by substituting in the first order conditions respectively, $h_{2}=1$ and $\lambda=0$. Case B is obtained by setting (3) hold with equality and $\mu=0$. The two cases are used as extreme exemplifications, but are not necessarily exclusive.

Notice that, while in general it is difficult to establish uniqueness in case B, for case A there is a simple sufficient condition. The partial derivative of (7) with respect to $h_{1}$ is in fact unambiguously negative when $\frac{\partial^{2} y_{\left(h_{1}+1\right) / 2}}{\partial h_{1}^{2}} \geq 0$, i.e. when the distribution of income is sufficiently skewed to the right. Under this condition, if an equilibrium $h_{1}^{*}$ exists, it is unique.

\section{Proof of proposition 3}

The mass of members will be smaller than $\left[0, h^{*}\right]$ if and only if the individual who was the marginal member under $\left\{y_{i}\right\}$-i.e. the $h^{*}$ defined by (4) - will drop out when 
the distribution becomes $\left\{\widetilde{y}_{i}\right\}$. In fact assumption (A5) and monotonicity of utility guarantee that if $h^{*}$ does not participate, no $j>h^{*}$ will. Consider the difference between the left hand sides of (3) under the new and under the old distribution:

$$
u\left(h^{*}\right)-\frac{C}{\int_{0}^{h^{*}} \widetilde{y}_{i} d i} \widetilde{y}_{h^{*}}-\left[u\left(h^{*}\right)-\frac{C}{\int_{0}^{h^{*}} y_{i} d i} y_{h^{*}}\right]=C\left(\frac{y_{h^{*}}}{\int_{0}^{h^{*}} y_{i} d i}-\frac{\widetilde{y}_{h^{*}}}{\int_{0}^{h^{*}} \widetilde{y}_{i} d i}\right)
$$

Given that individual $h^{*}$ was held at the reservation utility $\bar{u}$ under the initial distribution, for $y_{i}>0, \forall i$, a necessary and sufficient condition for $h^{*}$ to stay out of the group is that the above expression is negative, i.e. that (11) holds.

\section{The impact of inequality under restricted access}

For case A, where the initial group composition before the redistribution of income is $\left[h_{1}^{*}, 1\right]$, we can establish the following.

Claim: An increase in inequality taking the form described in (A4)-(A6) will decrease participation if and only if

$$
\frac{\int_{h_{1}^{*}}^{1} \widetilde{y}_{i} d i}{\int_{h_{1}^{*}}^{1} y_{i} d i}>\frac{\frac{\partial \widetilde{y}_{\left(h_{1}+1\right) / 2}}{\partial h_{1}}+\widetilde{y}_{h_{1}^{*}} \widetilde{y}_{\left(h_{1}^{*}+1\right) / 2}\left(\int_{h_{1}^{*}}^{1} \widetilde{y}_{i} d i\right)^{-1}}{\frac{\partial y_{\left(h_{1}+1\right) / 2}}{\partial h_{1}}+y_{h_{1}^{*}} y_{\left(h_{1}^{*}+1\right) / 2}\left(\int_{h_{1}^{*}}^{1} y_{i} d i\right)^{-1}}
$$

Proof. Follows from (7), observing that $-u^{\prime}\left(1-h_{1}\right)$ is monotone decreasing in $h_{1}$.

Notice that under mild sufficient conditions on the shape of the new income distribution, participation unambiguously decreases when $\widetilde{y}_{\left(h_{1}^{*}+1\right) / 2}<y_{\left(h_{1}^{*}+1\right) / 2}$, i.e. when the original median income member is poorer under the new distribution. ${ }^{34}$ That is the situation represented in Figure 2b.

\footnotetext{
${ }^{34}$ The sufficient condition is that, when evaluated at $h_{1}^{*}, \partial \widetilde{y}_{\left(h_{1}+1\right) / 2} / \partial h_{1}<\partial y_{\left(h_{1}+1\right) / 2} / \partial h_{1}$. In fact when $\widetilde{y}_{\left(h_{1}+1\right) / 2}<y_{\left(h_{1}+1\right) / 2}$ this guarantees that the right hand side of (A.6) is less than 1, while the left hand side is greater than one by construction.
} 


\section{Appendix B}

\section{Summary statistics}

\begin{tabular}{lll} 
& Mean & Std Dev \\
\hline & & \\
Age & 45.14 & 14.96 \\
Atkinson & .42 & .16 \\
Avg assets in village & 36.54 & 19.12 \\
Decision by vote & .70 & .46 \\
Disadvantage-misinformed & .11 & .31 \\
Distance farm mkt & 1.16 & 1.96 \\
Distance livestock mkt & 4.73 & 5.53 \\
Education & 4.51 & 3.87 \\
Female & .12 & .33 \\
Gen Entr (2) & .36 & .47 \\
Gini & .36 & .11 \\
Good or excellent functioning & .66 & .47 \\
Groups frequently interact & .72 & .45 \\
Heterog activity & 1.94 & 1.64 \\
Heterog education & 3.62 & .98 \\
HH size & 6.31 & 3.31 \\
Leaders different living & .33 & .47 \\
ln(Pop) in village & 12.49 & .35 \\
Members same living & .18 & .38 \\
Members all poor & .07 & .25 \\
Members mixed income group & .92 & .26 \\
Members same clan & .04 & .20 \\
Membership increased (4yrs) & .56 & .50 \\
Rainfall crit. month avg & 141.8 & 61.8 \\
Rainfall crit month std dev & 2.54 & .94 \\
Regions & & \\
Coast & .05 & .22 \\
Arid & .12 & .33 \\
Quasi-arid & .25 & .43 \\
Plateaux & .28 & .45 \\
South West Plain & .20 & .40 \\
Northern Highlands & .09 & .28 \\
Resid in village $\geq 10$ yrs & .86 & .35 \\
StdDevLogs & .78 & .22 \\
Temperature avg & 26.52 & 1.82 \\
Temperature std dev & 3.39 & 1.27 \\
Tourism & .06 & .25 \\
Tribal fragmentation & .33 & .25 \\
Very encouraged to participate & .66 & .47 \\
& & \\
\hline \hline & & \\
\hline
\end{tabular}


Table 1: Membership

\begin{tabular}{ll} 
& Mean \\
\hline \hline & .72 \\
Member of any group & .12 \\
Member of political group & .15 \\
Member of church group & .06 \\
Member of mosque/muslim group & .12 \\
Member of burial society & .05 \\
Member of women's group & .05 \\
Member of farmers' group & .01 \\
Member of cattle rearing group & .02 \\
Member of coop & .01 \\
Member of Rosca & \\
\hline
\end{tabular}

Source: author's calculations on the SCPS. 
Table 2: Group characteristics

Panel A: Organizational RUles

How become member?

\begin{tabular}{lllll}
\hline & Born & Required & Fee & Voluntary \\
Religious & .36 & .04 & .07 & .55 \\
Political & .02 & .13 & .35 & .51 \\
Economic & .02 & .16 & .19 & .63 \\
\hline \hline
\end{tabular}

Supported by agency? (Yes = 39\%)

\begin{tabular}{|c|c|c|c|c|}
\hline & Government & NGO & Foreign & Church \\
\hline Religious & .03 & .39 & .07 & .41 \\
\hline Political & .53 & .40 & .01 & .02 \\
\hline Economic & .13 & .54 & .03 & .07 \\
\hline \multicolumn{5}{|c|}{ Penalty if not pay fee? } \\
\hline & Expelled & Pay late & Nothing & \\
\hline Religious & .10 & .11 & .79 & \\
\hline Political & .38 & .29 & .32 & \\
\hline Economic & .39 & .16 & .45 & \\
\hline
\end{tabular}

Panel B: Members' heterogeneity

Ethnicity

\begin{tabular}{llll}
\hline & Same clan or tribe & Diff. tribes & Anyone \\
Religious & .01 & .30 & .69 \\
Political & .01 & .24 & .75 \\
Economic & .07 & .23 & .70 \\
\hline \hline
\end{tabular}

Make a living in the same way?

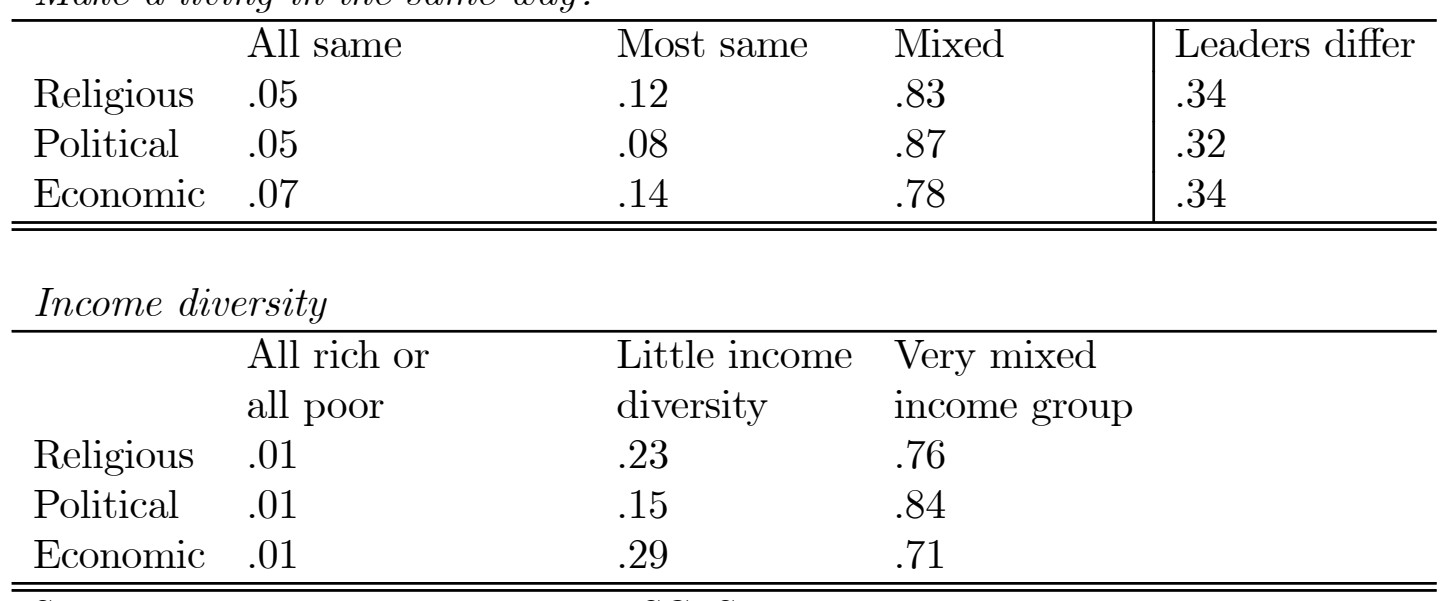

Source: author's calculations on the SCPS. 
Table 3: Basic regressions (marginal Probit coefficients) (Dependent variable $=1$ if member of a group)

\begin{tabular}{|c|c|c|c|c|}
\hline & [1] & [2] & {$[3]$} & [4] \\
\hline Age & $\begin{array}{l}-.0004 \\
(.002)\end{array}$ & $\begin{array}{l}-.0001 \\
(.002)\end{array}$ & $\begin{array}{l}-.0004 \\
(.002)\end{array}$ & $\begin{array}{l}-.0003 \\
(.002)\end{array}$ \\
\hline Female & $\begin{array}{l}.067 \\
(.047)\end{array}$ & $\begin{array}{l}.089^{*} \\
(.045)\end{array}$ & $\begin{array}{l}.070 \\
(.050)\end{array}$ & $\begin{array}{l}.097^{*} \\
(.045)\end{array}$ \\
\hline Education & $\begin{array}{l}.014^{* *} \\
(.006)\end{array}$ & $\begin{array}{l}.014^{* *} \\
(.006)\end{array}$ & $\begin{array}{l}.008 \\
(.006)\end{array}$ & $\begin{array}{l}.011^{*} \\
(.006)\end{array}$ \\
\hline $\mathrm{HH}$ size & $\begin{array}{l}.01 \\
(.006)\end{array}$ & $\begin{array}{l}.009 \\
(.006)\end{array}$ & $\begin{array}{l}.004 \\
(.007)\end{array}$ & $\begin{array}{l}.006 \\
(.006)\end{array}$ \\
\hline Resid. in village $\geq 10 \mathrm{yrs}$ & $\begin{array}{l}.046 \\
(.061)\end{array}$ & $\begin{array}{l}.034 \\
(.057)\end{array}$ & $\begin{array}{l}.040 \\
(.053)\end{array}$ & $\begin{array}{l}.05 \\
.059)\end{array}$ \\
\hline Avg assets in village & $\begin{array}{l}.003^{* *} \\
(.001)\end{array}$ & $\begin{array}{l}.005^{* *} \\
(.001)\end{array}$ & $\begin{array}{l}.003^{* *} \\
(.001)\end{array}$ & $\begin{array}{l}.005^{* *} \\
(.001)\end{array}$ \\
\hline $\ln ($ Pop) in village & $\begin{array}{l}-.031 \\
(.05)\end{array}$ & $\begin{array}{l}-.09^{*} \\
(.052)\end{array}$ & $\begin{array}{l}-.073 \\
(.052)\end{array}$ & $\begin{array}{l}-.09^{*} \\
(.055)\end{array}$ \\
\hline Heterog education & & $\begin{array}{l}.003 \\
(.020)\end{array}$ & $\begin{array}{l}.004 \\
(.023)\end{array}$ & $\begin{array}{l}.008 \\
(.022)\end{array}$ \\
\hline Heterog activity & & $\begin{array}{l}.044 \\
(.102)\end{array}$ & $\begin{array}{l}.017 \\
(.108)\end{array}$ & $\begin{array}{l}.046 \\
(.106)\end{array}$ \\
\hline Tribal fragmentation & & $\begin{array}{l}-.112 \\
(.084)\end{array}$ & $\begin{array}{l}-.121 \\
(.091)\end{array}$ & $\begin{array}{l}-.114 \\
(.085)\end{array}$ \\
\hline Gini & & $\begin{array}{l}-.436^{* *} \\
(.181)\end{array}$ & $\begin{array}{l}-.378^{*} \\
(.218)\end{array}$ & $\begin{array}{l}-.46^{* *} \\
(.193)\end{array}$ \\
\hline Indiv assets & & & $\begin{array}{l}.002^{* *} \\
(.001)\end{array}$ & \\
\hline Indiv assets`2 & & & $\begin{array}{l}-5.3 \mathrm{e}-06^{* *} \\
(2.3 \mathrm{e}-06)\end{array}$ & \\
\hline 1st assets quartile & & & & $\begin{array}{r}-.090^{*} \\
(.050)\end{array}$ \\
\hline 4th assets quartile & & & & $\begin{array}{l}.053 \\
(.049)\end{array}$ \\
\hline REGIONS & Yes & Yes & Yes & Yes \\
\hline No. obs. & 624 & 624 & 581 & 581 \\
\hline Pseudo Rsq & .06 & .07 & .07 & .07 \\
\hline Observed P & .73 & .73 & .73 & .73 \\
\hline Predicted P & .75 & .75 & .75 & .75 \\
\hline
\end{tabular}

Notes: ${ }^{*}$ denotes significance at the 10 percent level, ${ }^{* *}$ at the 5 percent level. Marginal probit coefficients calculated at the means. Standard errors corrected for heteroskedasticity and clustering of the residuals at the village level. 
Table 4: Inequality and relative wealth

(Dependent variable $=1$ if member of a group; Coefficients on 'Gini' reported)

\begin{tabular}{lcc} 
& Relatively "poor" & Relatively "rich" \\
Relative rank defined in terms of: & {$[1]$} & {$[2]$} \\
\hline \hline
\end{tabular}

[1] Objective wealth ${ }^{(a)}$

$-.160$

$-.578^{* *}$

[2] Subjective wealth ${ }^{(b)}$

$-.207$

$-.504^{* *}$

[3] Subjective overestimate ${ }^{(c)}$

$-.353$

$-.690^{* *}$

$(.254)$

$(.335)$

\footnotetext{
Notes:

${ }^{*}$ denotes significance at the 10 percent level, ${ }^{* *}$ at the 5 percent level.

Marginal probit coefficients calculated at the means. Standard errors corrected for heteroskedasticity and clustering of the residuals at the village level.

Each cell reports the estimated coefficient on 'Gini' from a separate regression. All regressions include individual, village, and region controls as in column 3 of table 3.

(a) "Relatively poor": individuals whose assets index is in the first two quintiles for their village; "Relatively rich": individuals whose assets index is in the top three quintiles for their village.

(b) "Relatively poor": individuals who define themselves 'very poor' or 'poor'; "Relatively rich": individuals who define themselves 'average', 'rich', or 'very rich'.

(c) "Relatively poor": individuals who put themselves in a rank equal or below that assigned to them by the community; "Relatively rich": individuals who put themselves in a rank higher than that assigned to them by the community.
} 
Table 5: Access rules and skewedness of income distribution

Inequality measure used:

Gen.Entr.(2) Gini Atkinson(2) StdDevLogs

OA groups

\begin{tabular}{lllll}
\hline \hline & & & & \\
Ineq. & -.068 & $-.403^{*}$ & $-.255^{*}$ & $-.195^{* *}$ \\
& $(.063)$ & $(.246)$ & $(.134)$ & $(.097)$ \\
[+1 std.dev.]. & {$[-.03]$} & {$[-.03]$} & {$[-.04]$} & {$[-.03]$} \\
& & & & \\
No. obs. & 581 & 581 & 581 & 581 \\
R sq. & .10 & .10 & .10 & .10 \\
RA groups & & & & \\
\hline \hline & & & & \\
Ineq. & $.153^{* *}$ & $.547^{* *}$ & .206 & .145 \\
& $(.052)$ & $(.256)$ & $(.137)$ & $(.099)$ \\
[+1 std.dev. $]$ & {$[.07]$} & {$[.04]$} & {$[.03]$} & {$[.02]$} \\
& & & & \\
No. obs. & 581 & 581 & 581 & 581 \\
R sq. & .08 & .08 & .08 & .08 \\
\hline \hline
\end{tabular}

* denotes significance at the 10 percent level, ${ }^{* *}$ at the 5 percent level.

Marginal probit coefficients calculated at the means. Standard errors corrected for heteroskedasticity and clustering of the residuals at the village level.

All regressions include individual, village, and region controls as in column 2 of table 3. 
Table 6: Group characteristics, by type

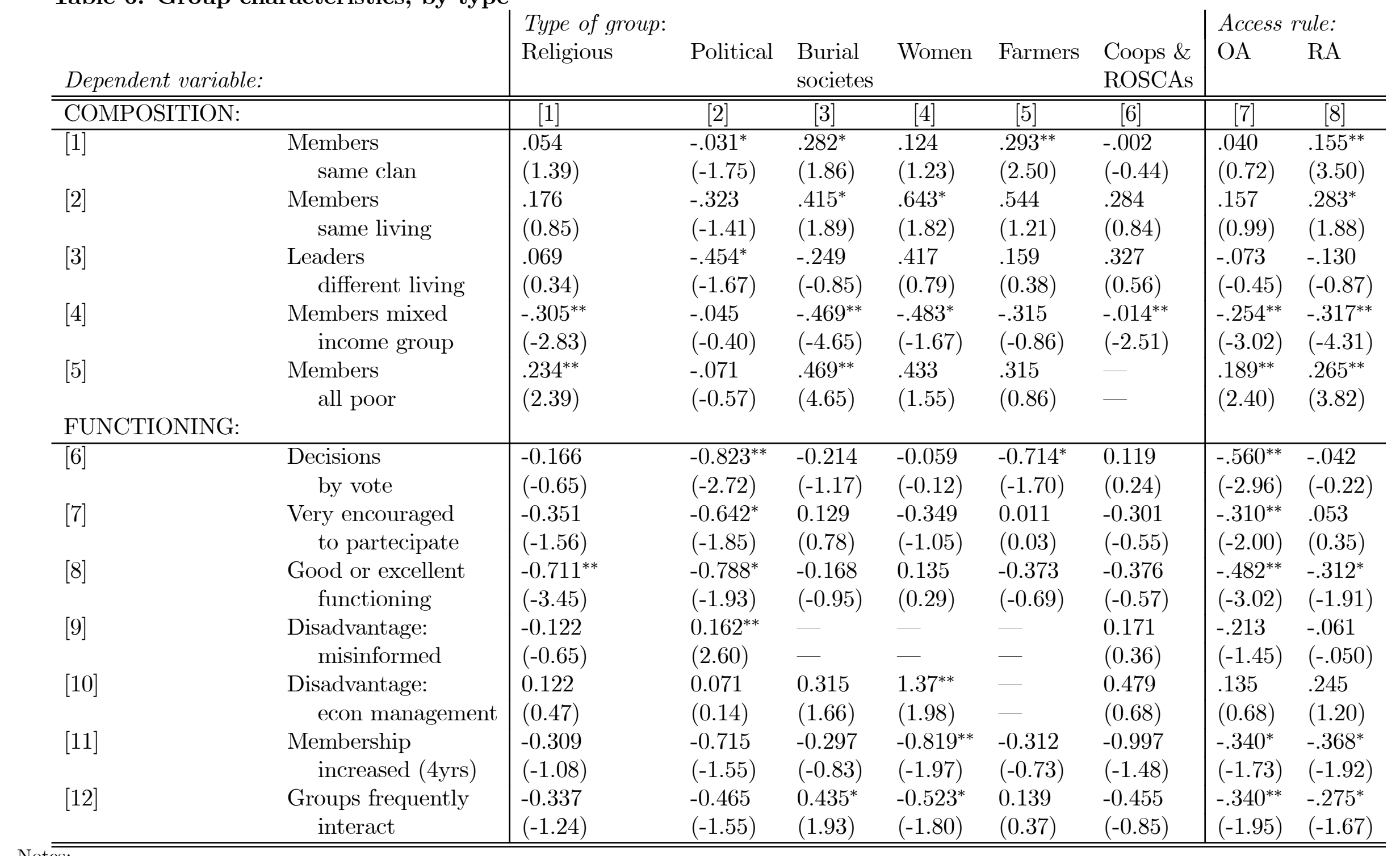

* denotes significance at the 10 percent level, ${ }^{* *}$ at the 5 percent level.

Marginal probit coefficients calculated at the means. Standard errors corrected for heteroskedasticity and clustering of the residuals at the village level. 
Figure 1: Open access group

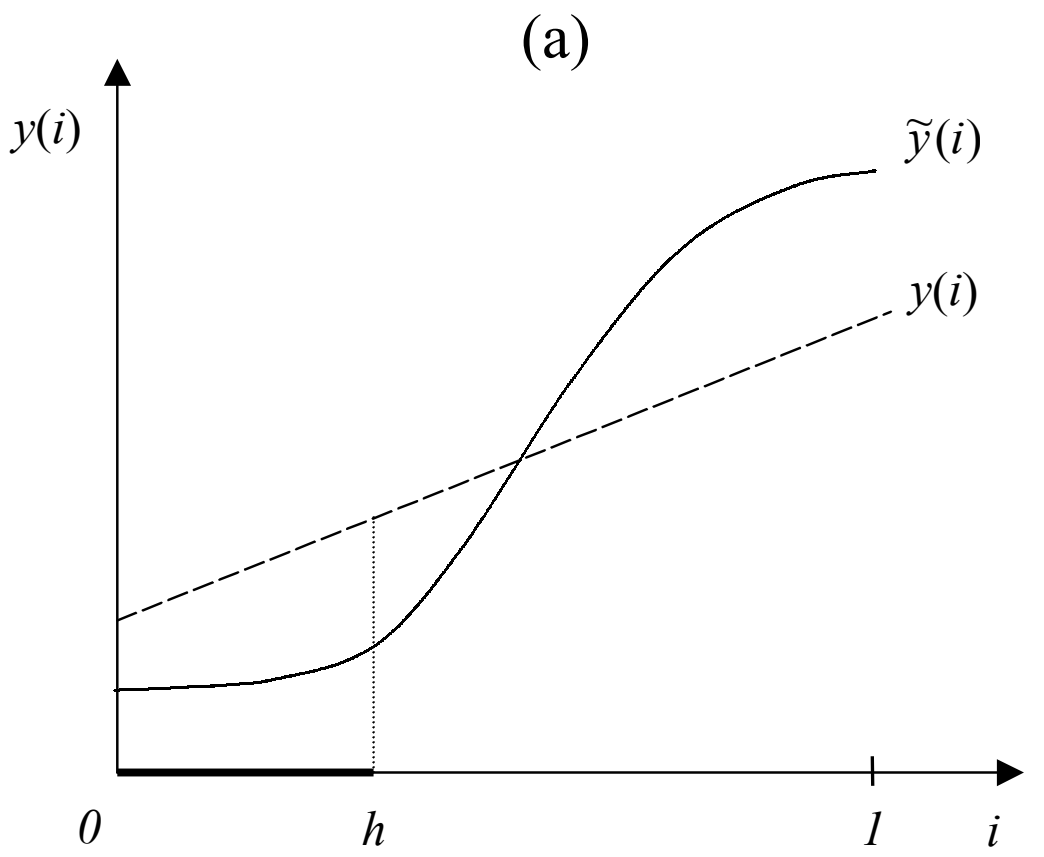

(b)

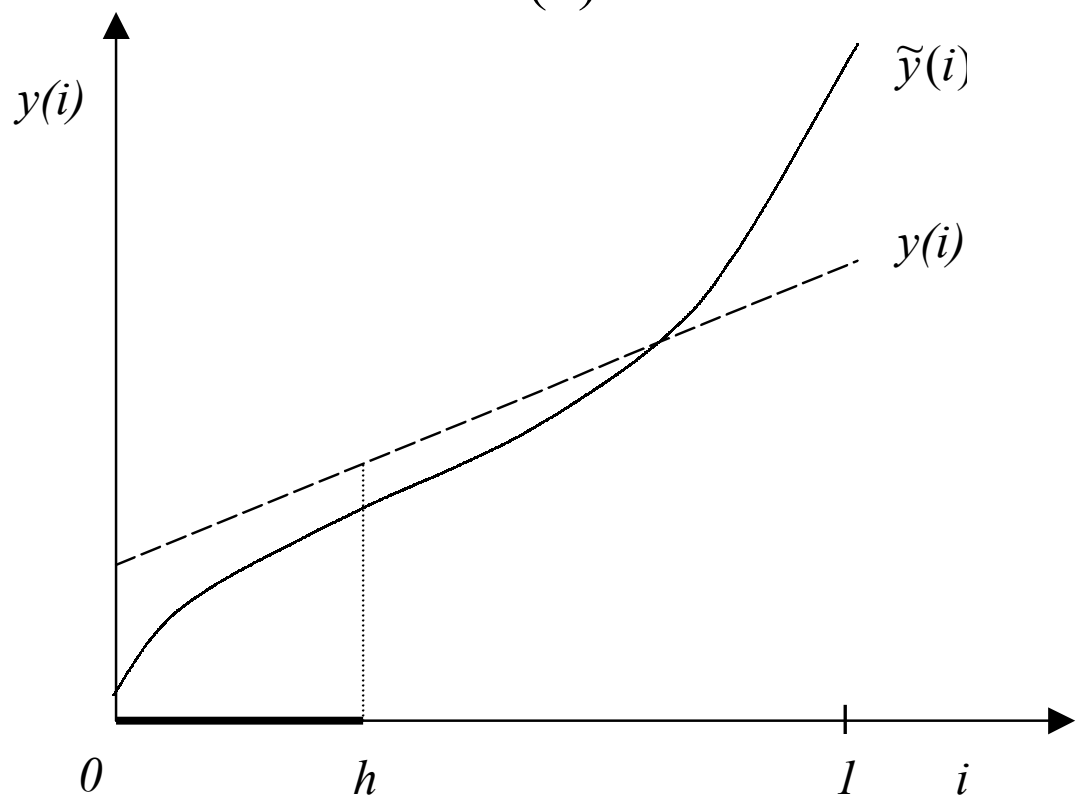


Figure 2: Restricted access group

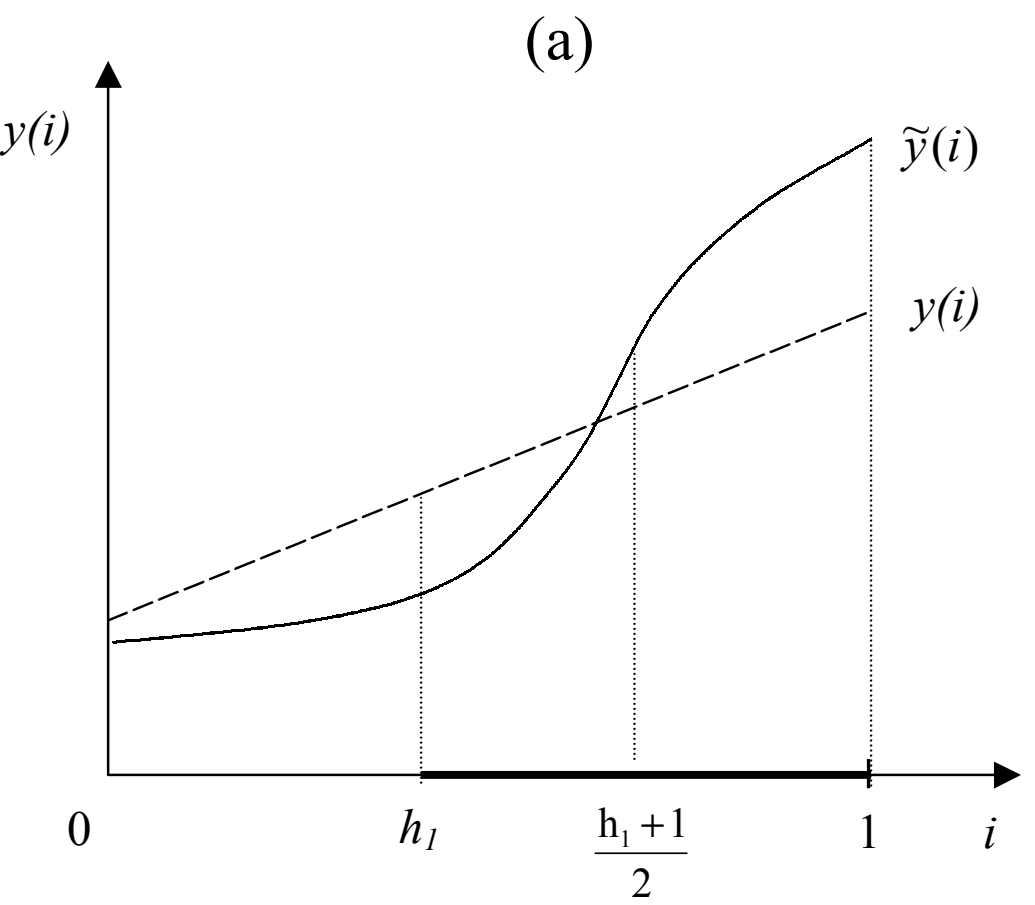

(b)

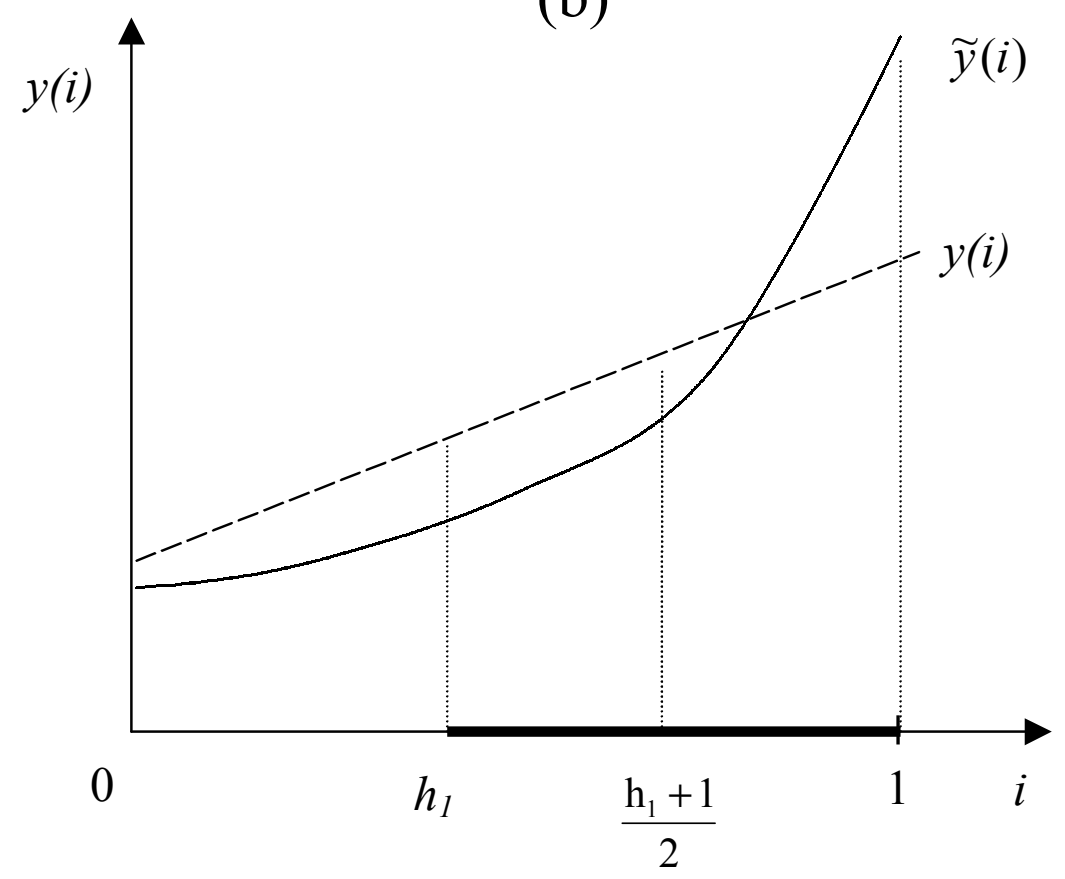

